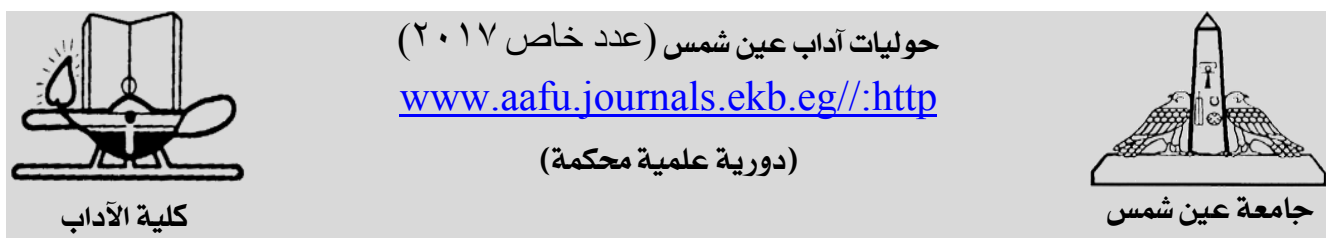

\title{
تقييم مشروع رقمنة الدوريات العلمية بجامعة المنصورة فى ضوك هعايير ضبط الدوريات المرقمنة
}

\author{
تسنيم على أحمد علي* - ت ت
}

قسم المكتبات و المعلوماتـ كلية الآداب ـ جامعة عين شمس

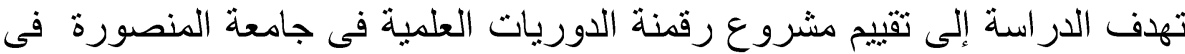

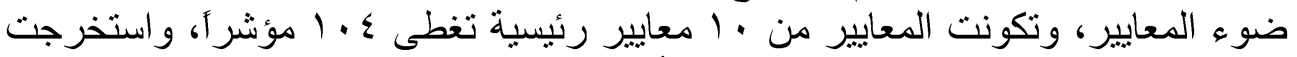

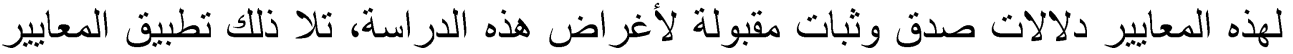

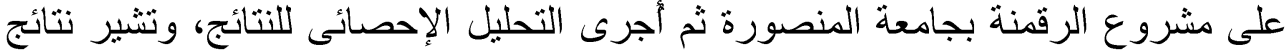

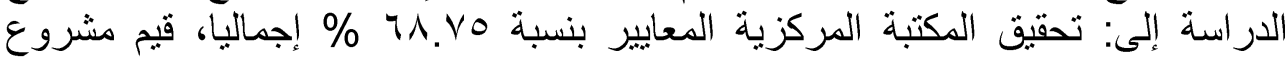

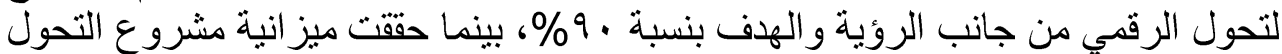

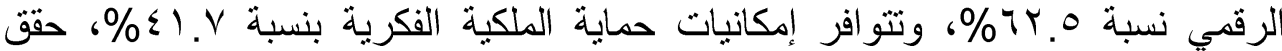

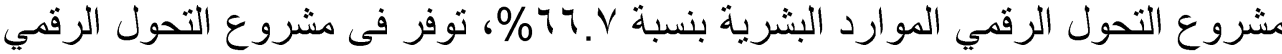

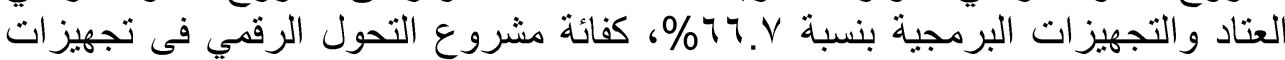

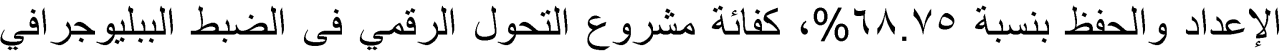

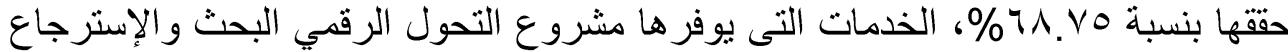

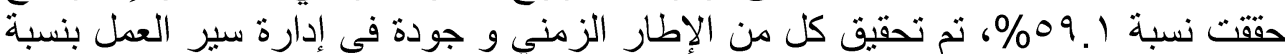

الكاكمات الافتاقيهة: التحول الرقمي، الرقمنة، مشاريع الرقمنة، الدوريات العلمية،

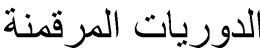


إن تحلل عملية الرقمنة يتم من خلال تحديد احتياجات المؤسسة، وصوغ الأفكار لتلبية هذه الاحتياجات، ترسم مرحلة تصميم المشروع رؤية واسعة للتأثير على الاحتياجات

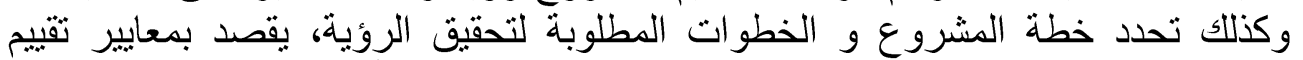

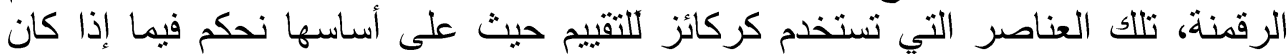

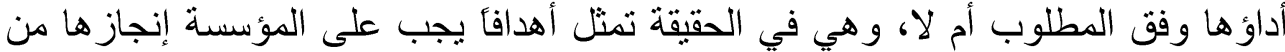

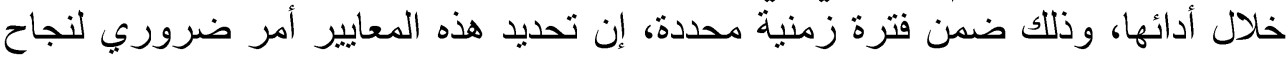

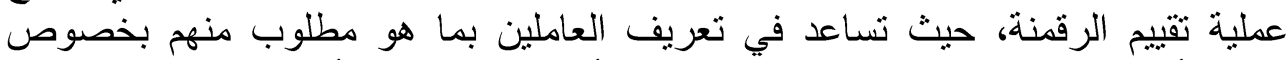

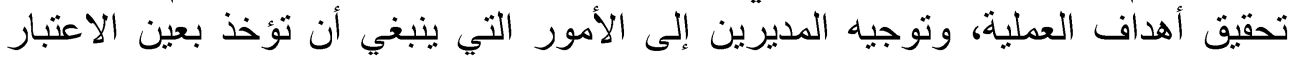

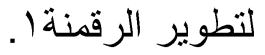

\section{Standards تعريف المعيار}

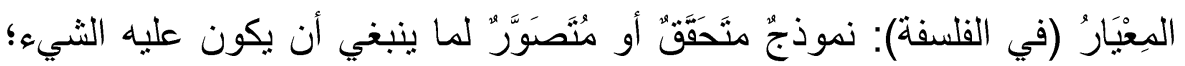

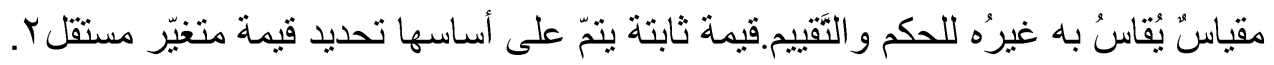

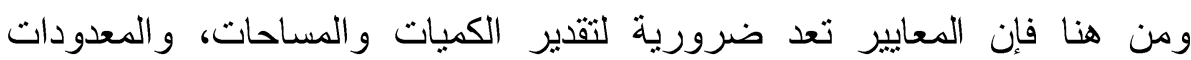

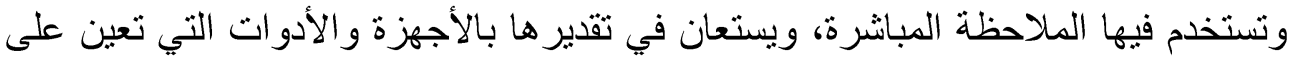
ضبط المقادير وتقنينها، استهدافأ للاقة و للوقاية والتهان والسلامة.

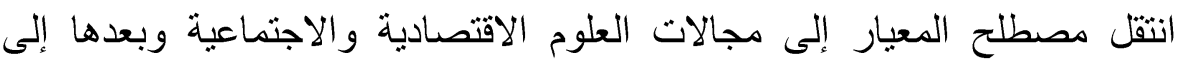
العلوم النفسية والتربوية؛ حيث يستعمل المصطلح بصورة مجازية، في اختبار ات الأكاء

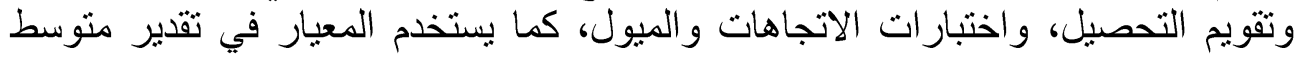

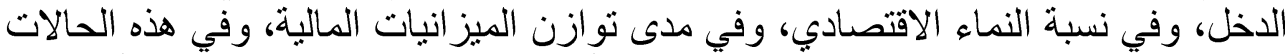

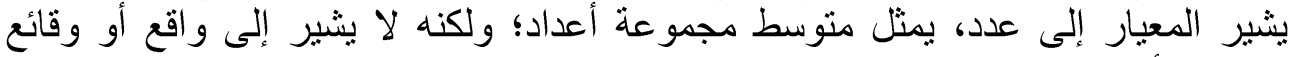

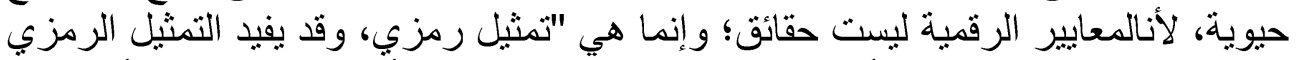

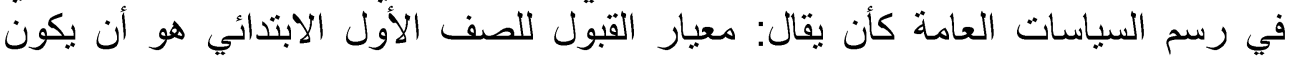

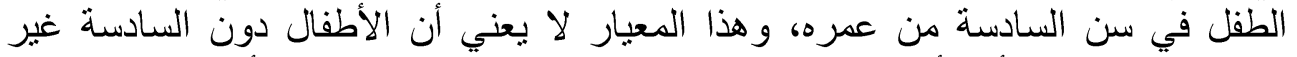

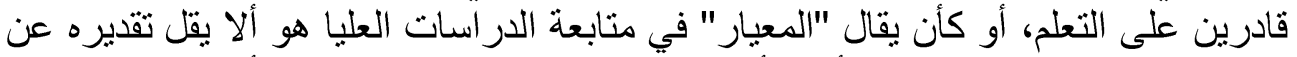

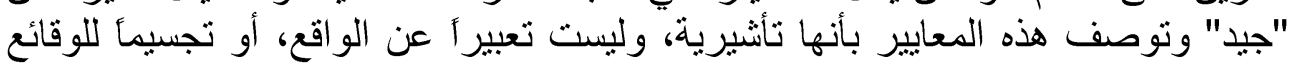

\section{تعريف المؤشرات indicators}

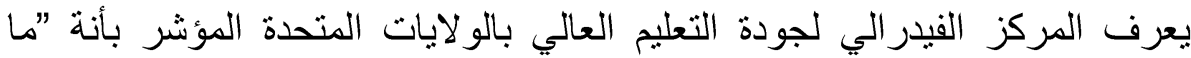

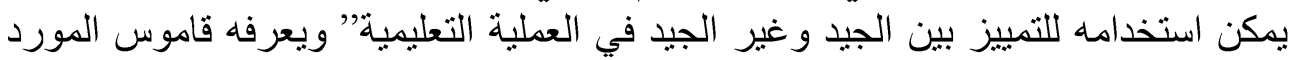

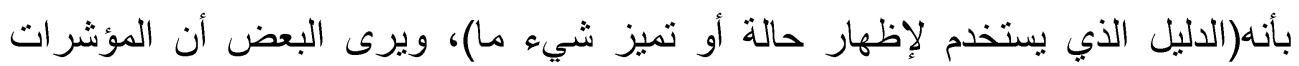

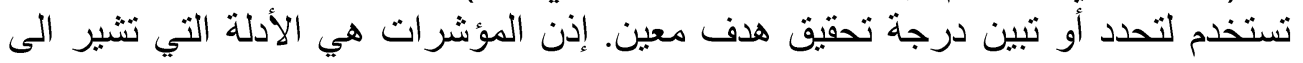

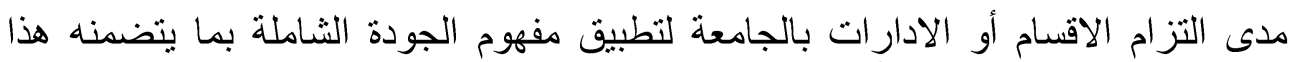

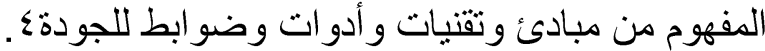

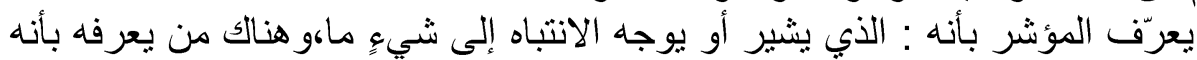

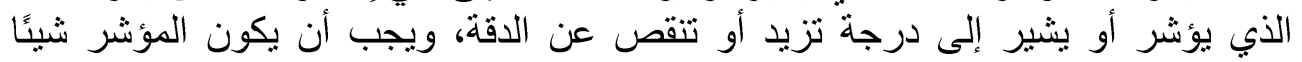

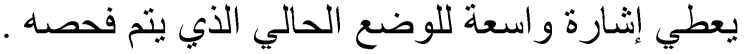




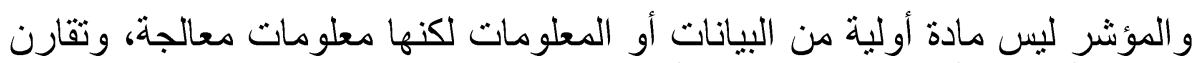

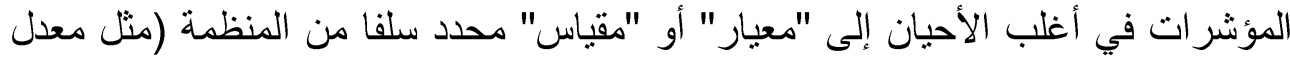

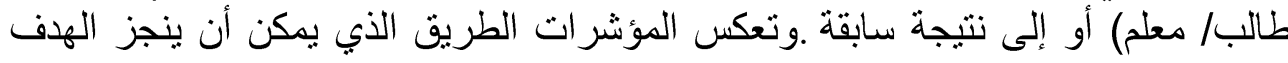

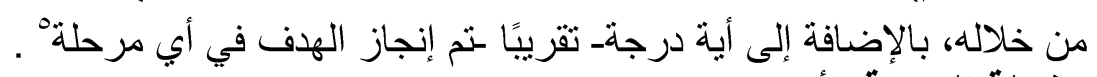

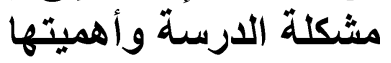

تلاحظ الباحثة عدم تطبيق المعايير عند البده فئه فئه تطبيق مشروع رقمنة الدوريات

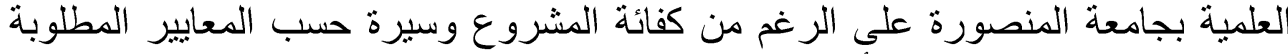

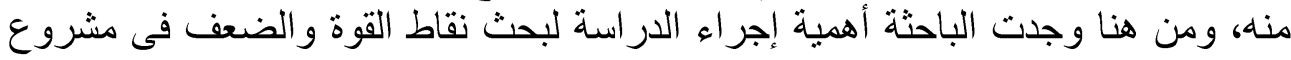

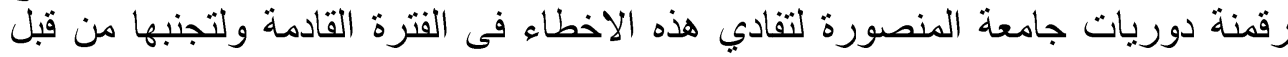

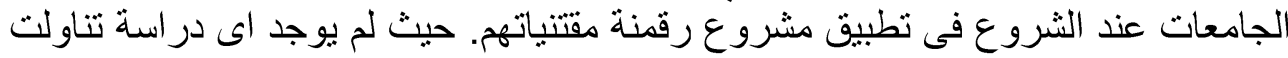

هذا الموضة المعاتة

تتبع أهمية الدر اسة من كونها أول در اسة لتقييم مشروع رقمنة الدوريات فى جامعة

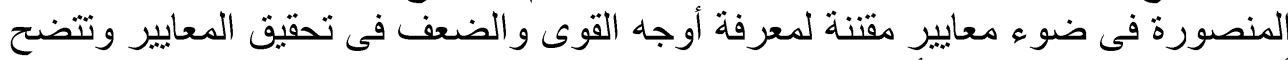

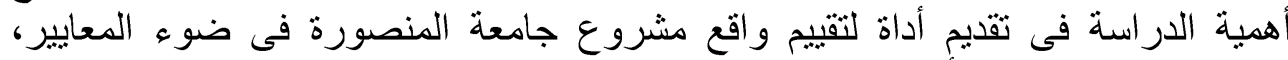

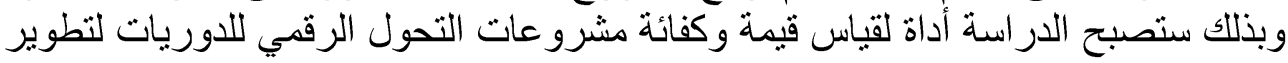
ووضع خطط ملائمة للعمل على تطوير المشور عات. أهداف الاراسة فئة

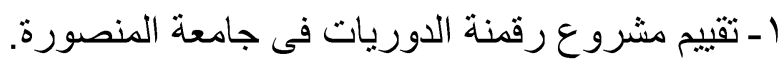
Y ـ تحديد أوجه القصور لكي تتمكن المكتبة من تفاديها فى المرحلة القادة القادة.

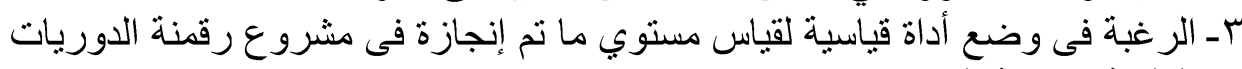

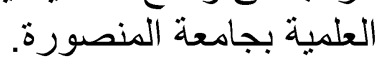

ع- رفع النتائج و التوصيات للمكتبة المركزية لإتخاذ اللازم نحول تطوير عملية الرقمنة.

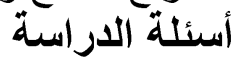

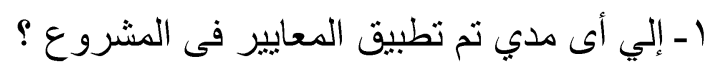

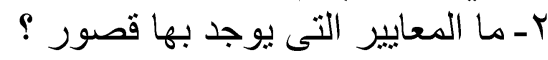

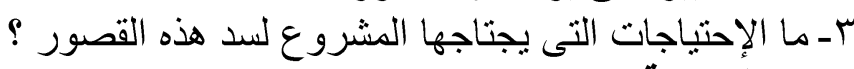
حدود الأراسة مأبات تناولت الدر اسة مشروع رقمنة دوريات جامعة المنصورة منذ بداية المشروع وحتي $r \cdot 17 / \varepsilon / 1$ مجتمع الدراسة

تتكون عينة الدراسة من أعداد دوريات جامعة المنصورة المنشورة في الكليات

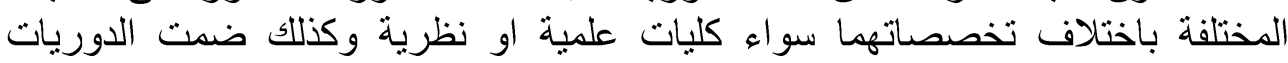

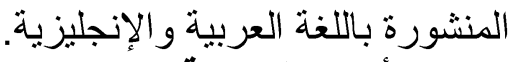
منهج وأدارة الاراسة اللغة التربة اعتمدت الدراسة على المنهج المسحي الميداني المعتي المتمد على العينة، بإعتباره أنسب

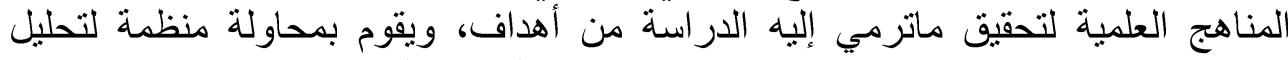

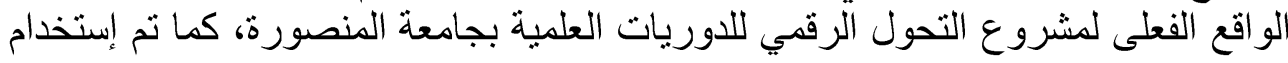




\begin{tabular}{|c|c|c|}
\hline تسنيم على أحمد علي & \multicolumn{2}{|c|}{ تقييم مشروع رقمنة الدوريات المرقير العلمية بجامعة المنصورة فو } \\
\hline \multicolumn{3}{|c|}{ 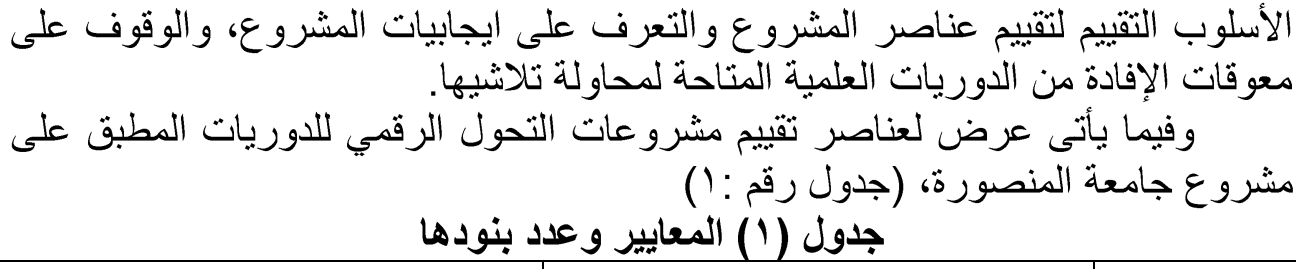 } \\
\hline عدد البنود & المعيار & مسلسل \\
\hline IT & الرؤية و الهذف & .1 \\
\hline$\Lambda$ & ميز انية المشروع & $r$ \\
\hline Ir & حقوق الملكية الفكرية & $r$ \\
\hline 7 & الموارد البشرية & $\varepsilon$ \\
\hline ir & العتاد و التجهيز ات البرمجية & .0 \\
\hline 17 & تجهيز ات الإعداد و الحفظ & .7 \\
\hline 10 & الضبط البيليوجر افي للدوريات المرقمة &.$V$ \\
\hline YY & البحث والإسترجاع &.$\wedge$ \\
\hline 0 & الإطار الزمني & .9 \\
\hline 0 & إدارة سير العمل & $.1 \cdot$ \\
\hline
\end{tabular}

\section{: الار اسات السابقة}

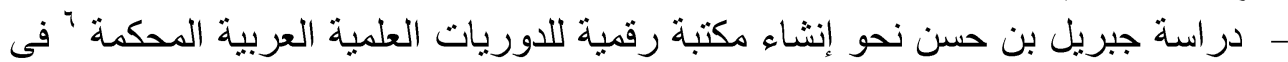

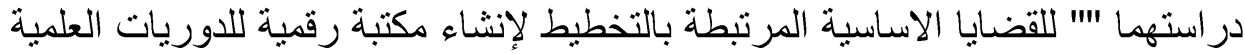

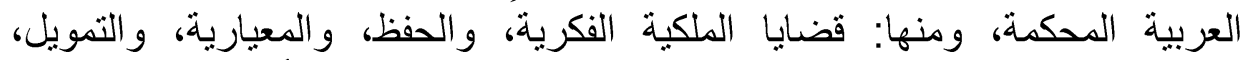

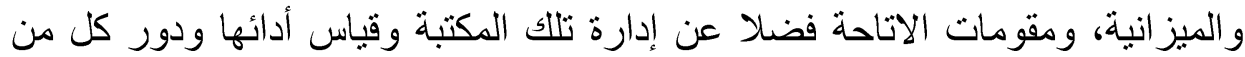

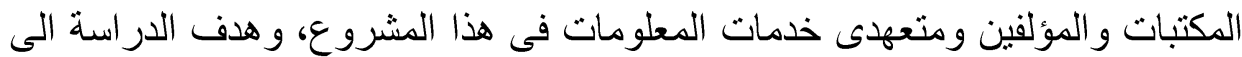

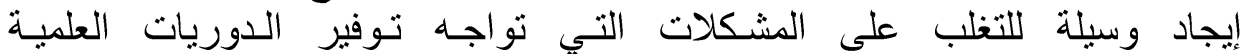
العربية،بحيث تتم إناحتها للباحثين في المكتبات الأكاديمية بالمملكة العربية السية السعودية، بسر عة وسهولة وبتكلفة أقل.

و استعانت هذه الدر اسة بالمنهج بالمنهج الوصفي التحليلي مستعينة بالأساليب البحث

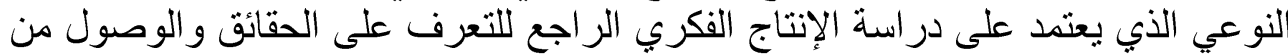

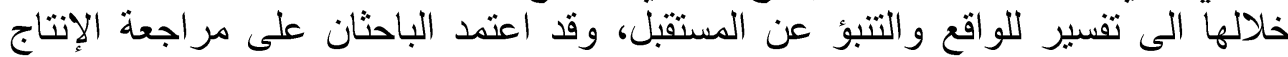

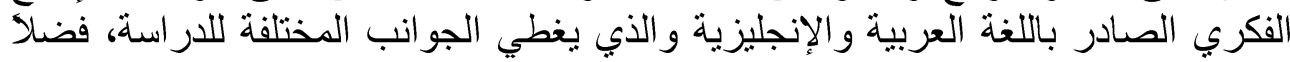

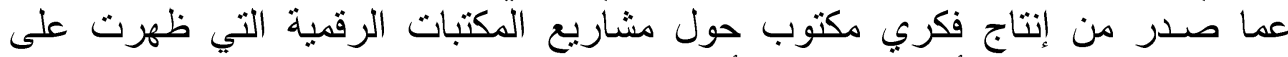

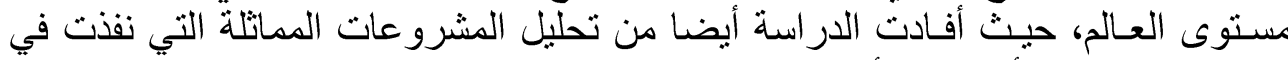

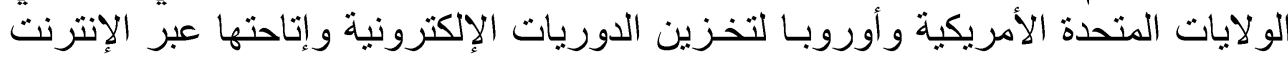

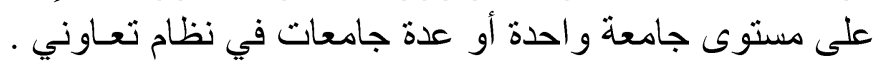




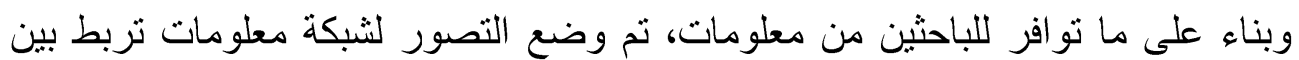

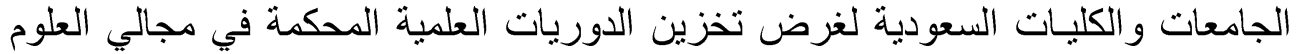

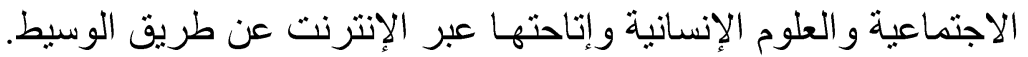

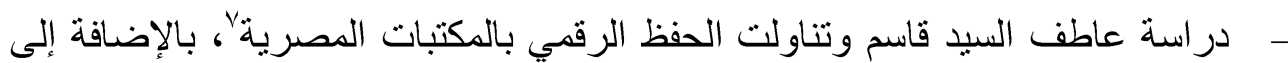

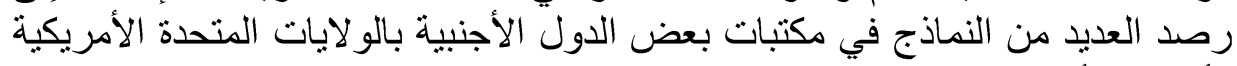
وأوروبا وأستر البا .

وقد عرفت الدراسة بأسس ومفاهيم الحفظ الرقمي وأهدافه ومتطلباته وتحدياته

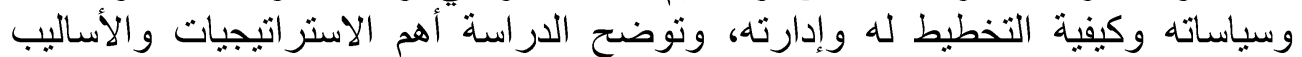

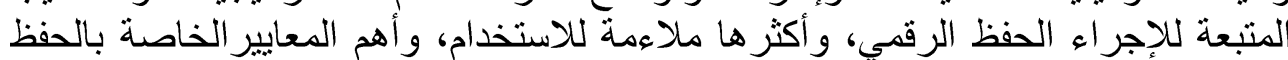

- در اسة نجلاء زكى ^ التحويل الرقمى لمقتنيات مكتبات اتحاد الإذاعة و التلفزيون: دراسة

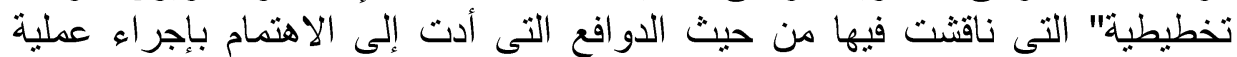

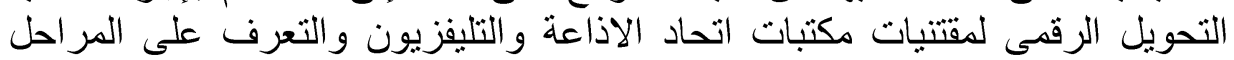

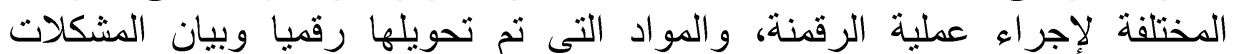
و الصعوبات التى ظهراء الأتهية ألثاء إجر اء العملية.

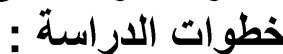

1- تحديد قائمة بالمعايير الخاصة بالتحول الرقمي للاوريات المرقمنة

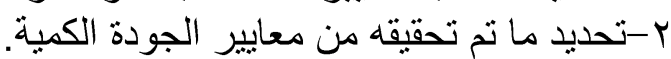

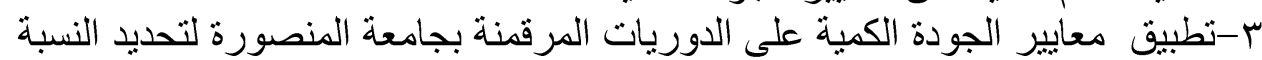

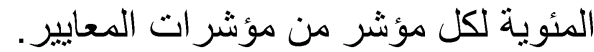

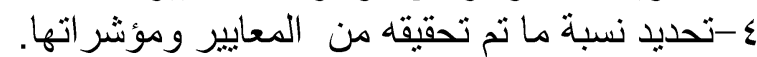

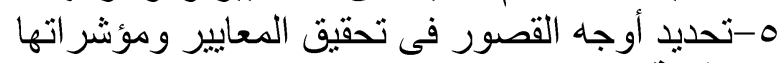

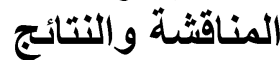

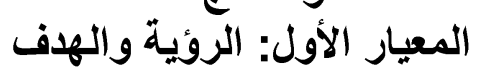

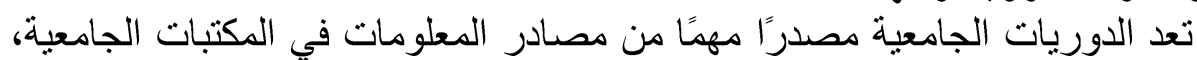

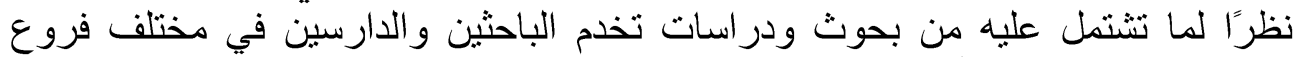

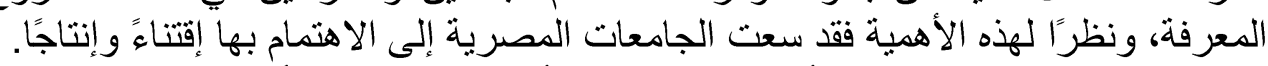

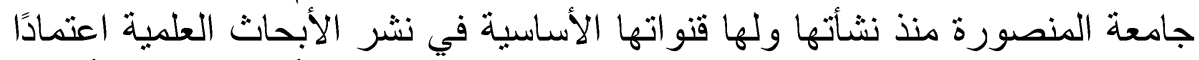

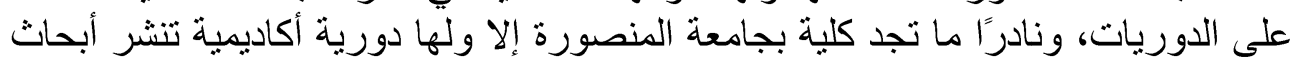

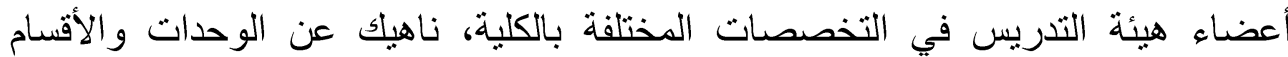
الأكاديمية في الكليات المختلفة، كما أنها تعد إضافة للمعات المعرفة البشرية.

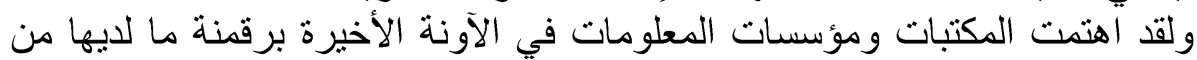

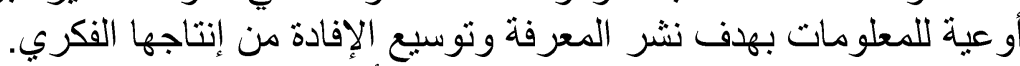

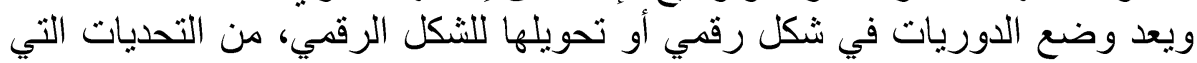

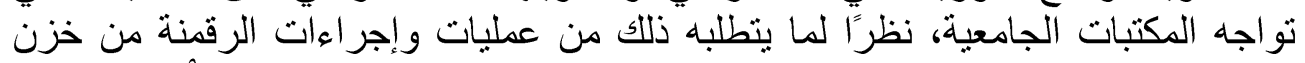

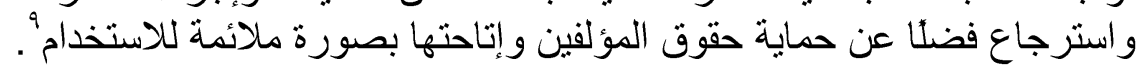

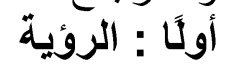

تتبثق رؤيتها من خلال تبني المكتبة المركزية بناء مستودع رقمي شامل الدوريات العلمية في شتى التخصصات العلمية لاعم العملية التعليمية وللحفاظ بلى على الأصول الؤية الورقية 
ولرفع مستوى الجامعة عالميًا وتلبية احتباجات المستقيدين على مستوى الجامعات المصرية

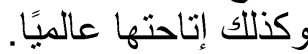

ثنانيًا : الهدف

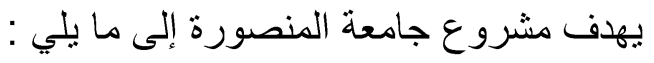

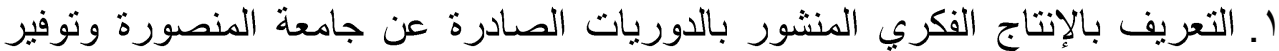

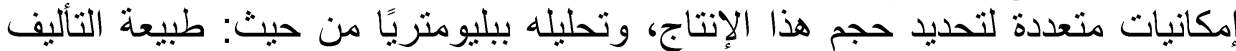

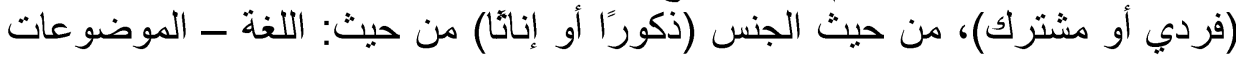
- السنو ات؛ بما بساهم في إلقاء الضوء على على مظاهر القوة و الضعف في هذا الإنتاج . r. خدمة الباحثين من خلال تيسير عمليات البحث والاسترجاع في مقالات هذه الدوريات

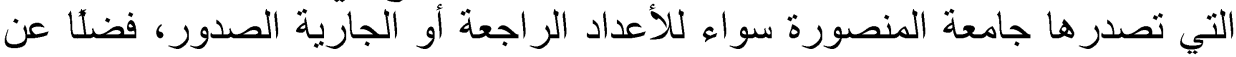

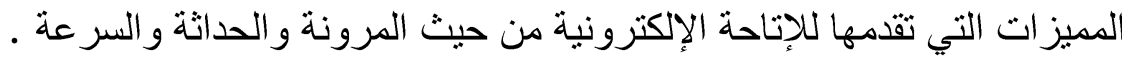
r. توفير كثافات شاملة للدوريات الصادرة عن الجامعات المصرية لسد العجز في هذا

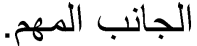

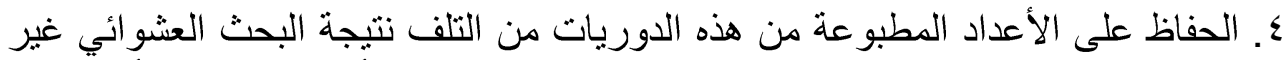

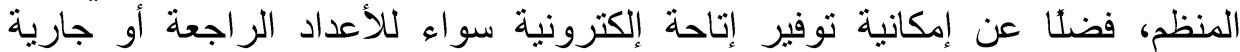
الصدور لهذه الدوريات.

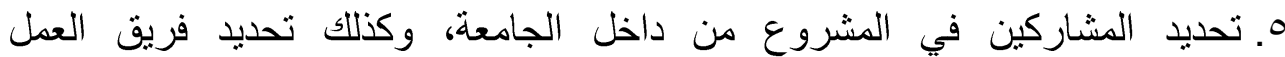

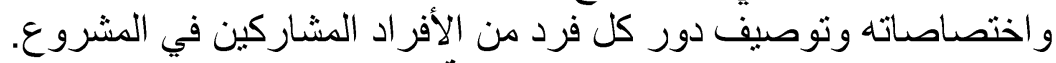

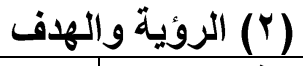

\begin{tabular}{|c|c|c|c|}
\hline$y$ & نعم & الرؤية و المهمة & عدد البنود \\
\hline & $\sqrt{ }$ & صياغة الهدف من المشروع & .1 \\
\hline & $\sqrt{ }$ & 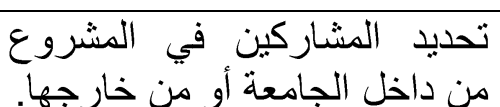 & $r$ \\
\hline & $\sqrt{ }$ & تحشيد فئات المستفيدين من & r \\
\hline & $\sqrt{ }$ & ت تحديد المستخدة. & . \\
\hline & $\sqrt{ }$ & الفكر التعاوني بين المكتبات. & .0 \\
\hline$\sqrt{ }$ & & البياحات المحتوى عالميًا عبر قو اعد & .7 \\
\hline & $\sqrt{ }$ & اللمواد المر اد رقمن الخصائص المادية & $v$ \\
\hline & $\sqrt{ }$ & تحديد حقوق الملكية الفكرية. &.$\wedge$ \\
\hline & $\sqrt{ }$ & تحديد المكان الذي ستقام به عملية & 9 \\
\hline
\end{tabular}




\begin{tabular}{|c|c|c|c|}
\hline & $\sqrt{ }$ & طرق المرقمة. & .1 . \\
\hline & $\sqrt{ }$ & الجامعلين. في المشروع من داخل & .11 \\
\hline$\sqrt{ }$ & & لالاستعانه بفريق من الخارج & $.1 Y$ \\
\hline
\end{tabular}

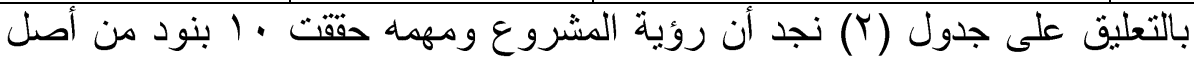

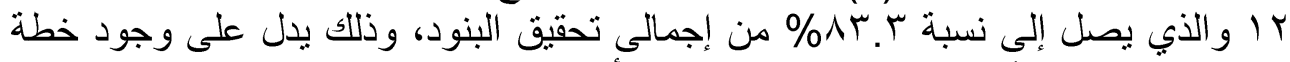

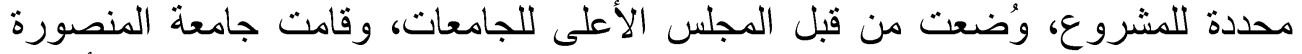

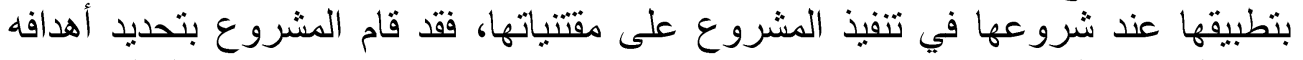

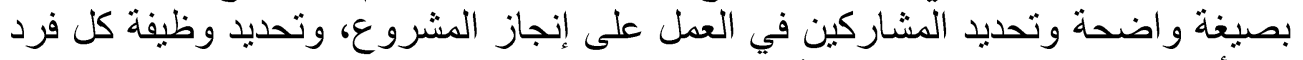

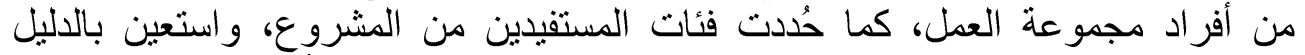

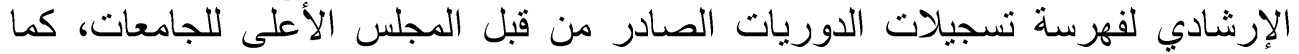

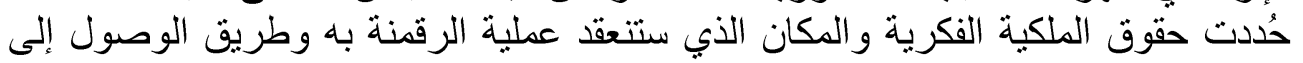

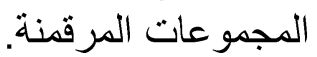

\section{المعيار الثاني : ميزانية المشروع المئة}

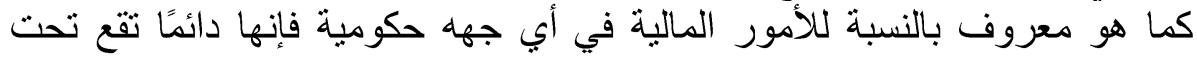

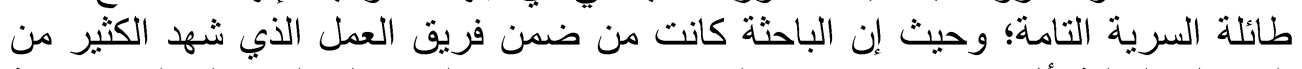

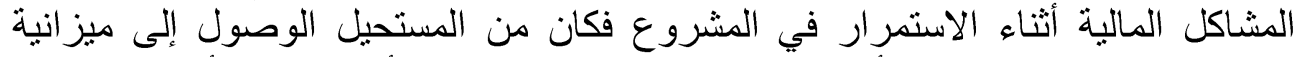

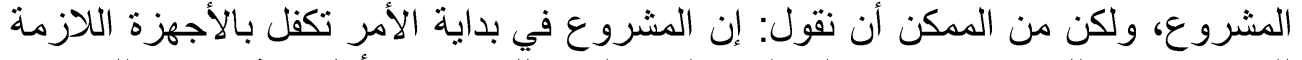

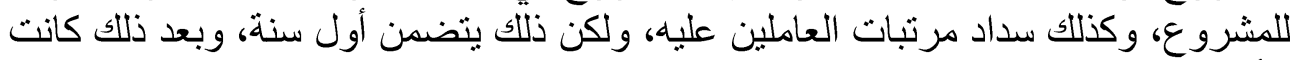

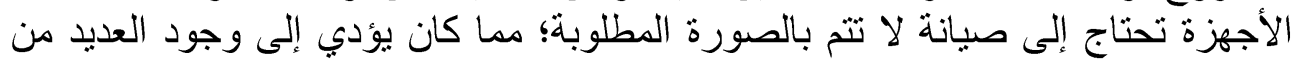

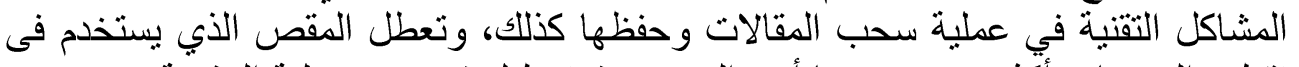

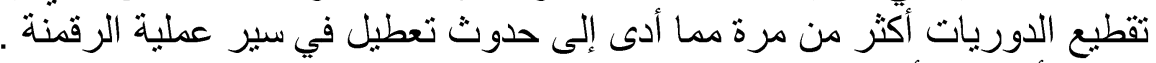

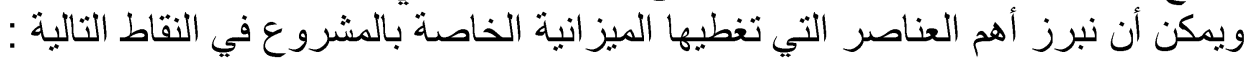

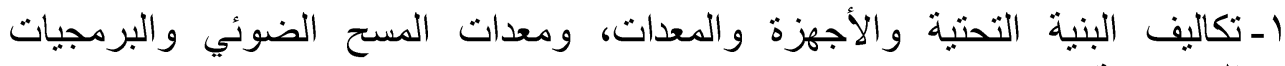

المستخدمة.

r-رسوم نقل الدوريات من الكليات إلى المكتبة المركزية و عمليات الصيانة و التجليد.

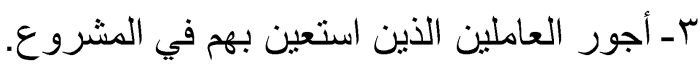
ع - رسوم دور ات تدريب وتأهيل العاملين.

ه - تكاليف وسائط التخزين و والحفظ.

7ـ تكاليف الصيانة المستمرة للاوريات المرقنة، المتمثلة في صيانة الأجهزة وشراء

جذول (ب) ميزانية المشروع البرمجيات و الثبكات.

\begin{tabular}{|c|c|c|c|}
\hline$y$ & نعم & ميز انية المشروع & عدد البنود \\
\hline & $\sqrt{ }$ & وجود ميز انية ثابتة للمعدات. & .1 \\
\hline & $\sqrt{ }$ & وجود ميز انية ثابتة للبر مجيات. & $r$ \\
\hline & $\sqrt{ }$ & تدريب الضوائي. الكور البشرية على & $r$ \\
\hline
\end{tabular}




\begin{tabular}{|c|c|c|c|}
\hline \multicolumn{2}{|c|}{ تسنيم على أحمد علي } & \multicolumn{2}{|c|}{ 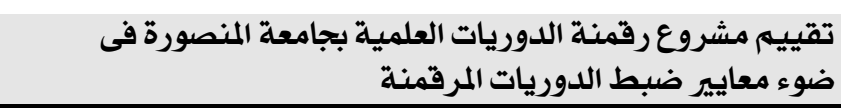 } \\
\hline & $\bar{l}$ & ضدريب الجودة. الكوادر البشرية على & $\varepsilon$ \\
\hline & $\sqrt{ }$ & إنشاء معايير الميتاداتا. البشرية على الكية & .0 \\
\hline$\sqrt{ }$ & & فقط. اعتماد المكتبة على قدرتها الذاتية & .7 \\
\hline & $\sqrt{ }$ & تمويل خارجي. الجامعة في التمويل على &.$V$ \\
\hline$\sqrt{ }$ & & توفير مصالة إنقادع التمويل. بديلة للتمويل في &.$\wedge$ \\
\hline
\end{tabular}

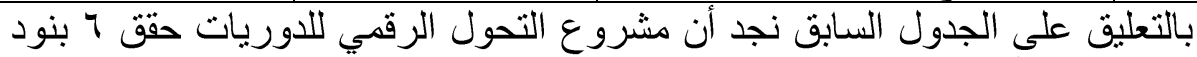

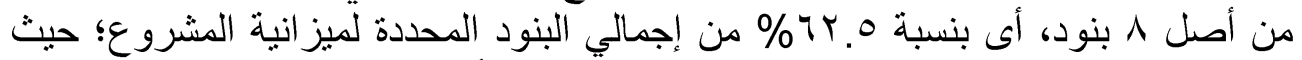

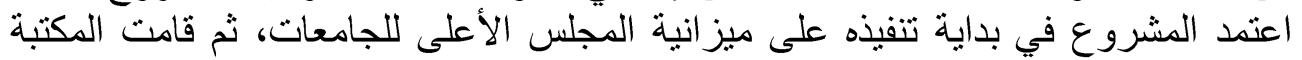

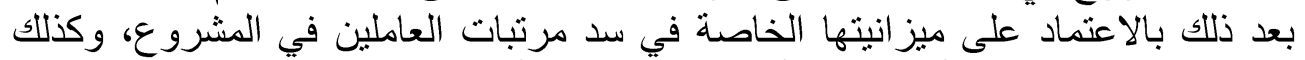

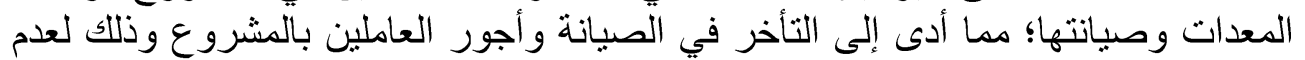

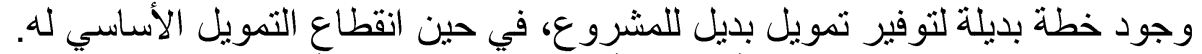

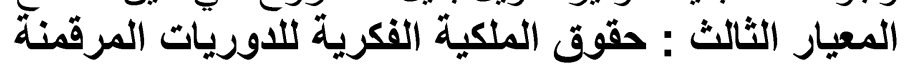

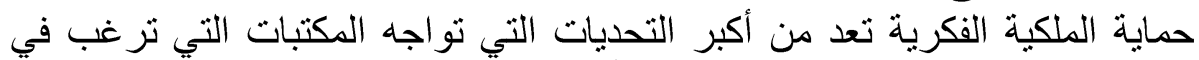

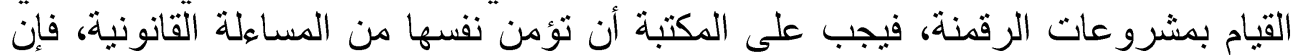

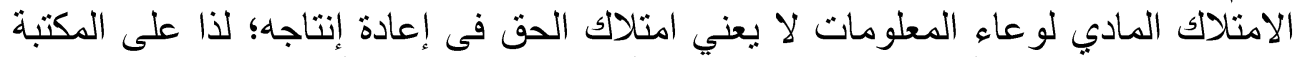

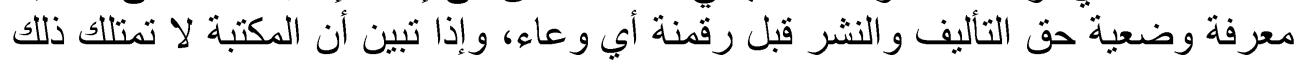

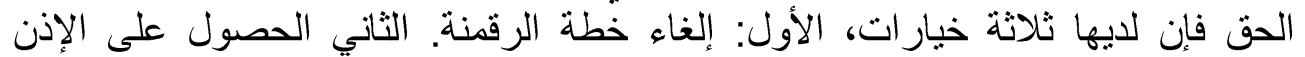

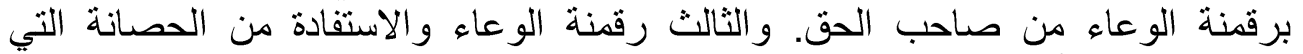
توفر ها بعض الأنظمة مثل الاستخدام العادل.

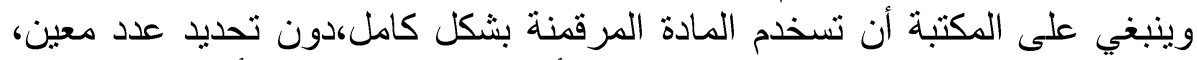

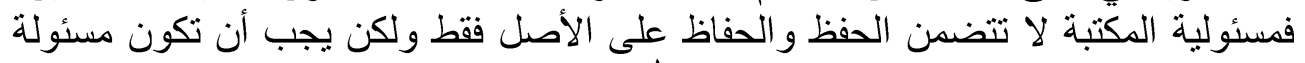

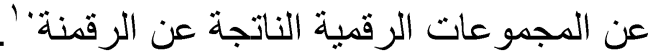

جدول (؛ ) حقوق الملكية القكرية

\begin{tabular}{|c|c|c|c|}
\hline$\gamma$ & نعم & حقوق الملكية الفكرية للاوريات & عدد البنود \\
\hline$\sqrt{ }$ & & صففحات حد معين من تصفح عدد & .1 \\
\hline & $\sqrt{ }$ & 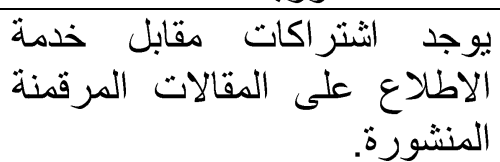 & $Y$ \\
\hline & $\sqrt{ }$ & الاطوجد تحديد لفئات المستقيدين من المقالات. & $r$ \\
\hline$\sqrt{ }$ & & باللغة المشروبة المنشورة النسخ من المقالات & $\varepsilon$ \\
\hline
\end{tabular}




\begin{tabular}{|c|c|c|c|}
\hline$(r \cdot) V_{0}$ & & عين شمس & حوليات \\
\hline & $\sqrt{ }$ & باللتخة الإنجليزية المنشخ من المقالات & 0 \\
\hline \multirow[t]{3}{*}{$\sqrt{ }$} & & 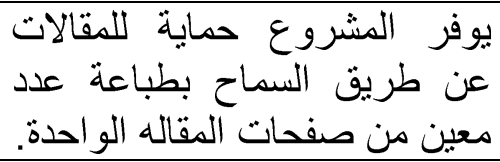 & .7 \\
\hline & $\sqrt{ }$ & وجتود كلمة سر الاطلاع على المقالات &.$V$ \\
\hline & $\sqrt{ }$ & المقالات ل لمشتخدمي النظام فقط. على. &.$\wedge$ \\
\hline$\sqrt{ }$ & & التيح النظات لغيرو المسجلين على على الاطلاع & 9 \\
\hline$\sqrt{ }$ & & يملثفر الصناحية. & .1 \\
\hline$\sqrt{ }$ & & يتم إرفاق العلامات المائية الرقمية الرقية & .11 \\
\hline$\sqrt{ }$ & & الدوريات وضع التوقيعة الرقمي * على & .14 \\
\hline
\end{tabular}

* التشفير هو عملية تحويل المعلومات باستخدام خوارزمية التشفير لنقلها عبر الثبكات غير التهن

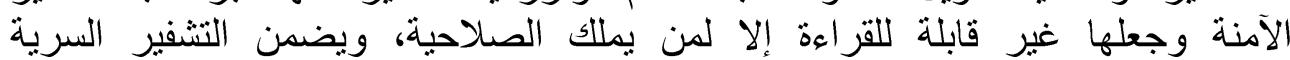

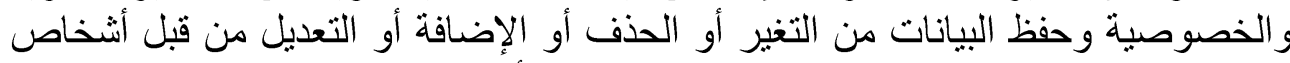

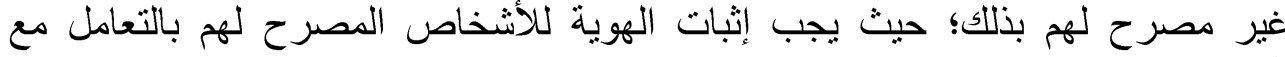
البيانات.

* التوقيع الرقمي هو عبارة عن شفرة رقمية (مجموعة من البتات Bit) مرفقة بكيان رقمي

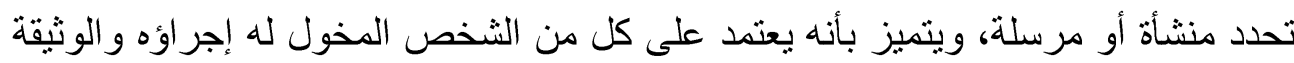

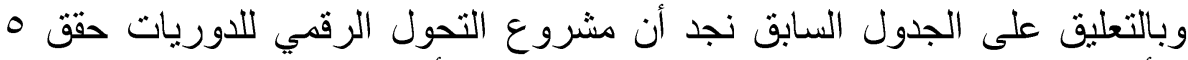

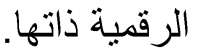

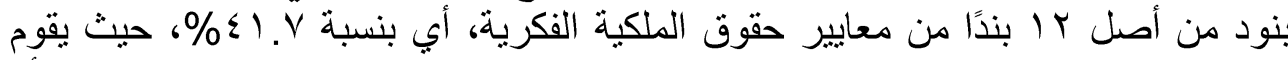

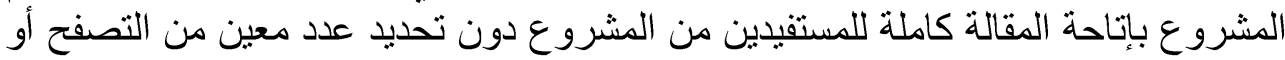

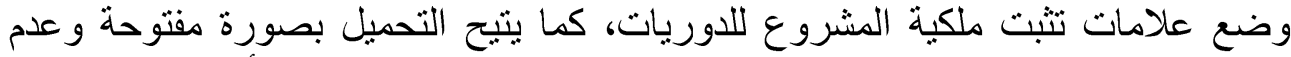

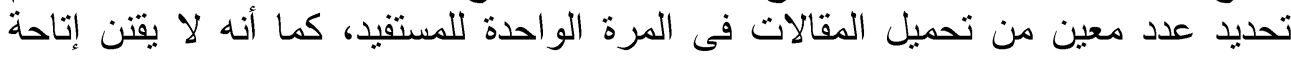

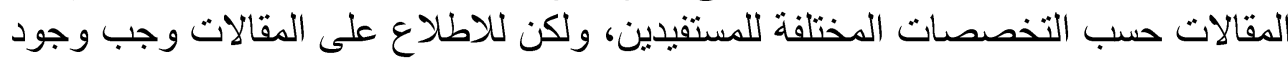

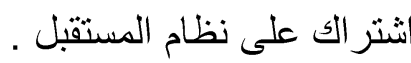

\section{المعيار الرابع : الموارد البشرية المبية}

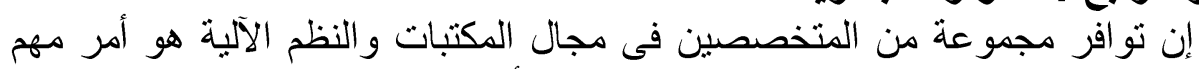

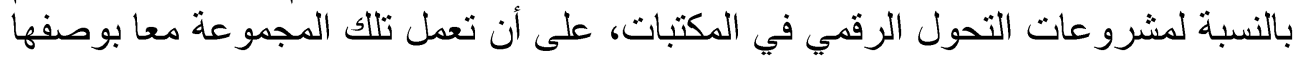

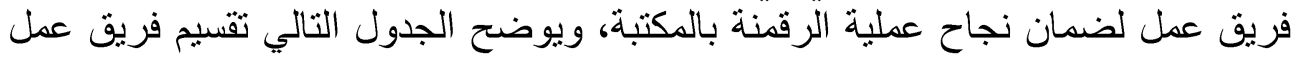

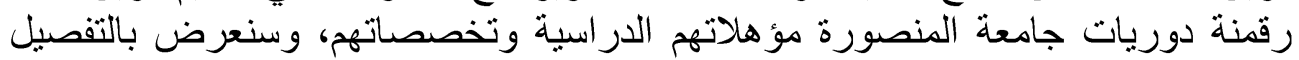
المهام المنوط بفريق العمل القيام بها بشكل. 


\begin{tabular}{|c|c|c|c|c|}
\hline تسنيم على أحمد علي & \multicolumn{4}{|c|}{ ضقوء معايير ضروعبط رقمنة الدوريات المرقمنة العلمية بجامعة المنصورة فى } \\
\hline \multicolumn{5}{|c|}{ جدول رقم (0) تقسيم فريق العمل حسب المؤهل الدراسي } \\
\hline \multicolumn{5}{|c|}{ حسب المؤهل الدر اسي } \\
\hline \multicolumn{2}{|c|}{ متعاقدون ومؤقتون } & \multicolumn{3}{|c|}{ مثبتون } \\
\hline ليسانس /بكالوريوس & ماجستير & ليسانس /بكالوريوس & دكتور اة & ماجستير \\
\hline$\Lambda$ & - & 19 & 1 & $r$ \\
\hline \multicolumn{3}{|c|}{$r$. } & \multicolumn{2}{|r|}{ الإجمالي } \\
\hline
\end{tabular}

\begin{tabular}{|c|c|}
\hline \multicolumn{2}{|c|}{ حسب التخصص } \\
\hline تخصصات أخري & مكتبات ومعلومات \\
\hline 0 & ro \\
\hline$r$ & الاجمالى \\
\hline
\end{tabular}

جدول رقم V) تقسيم فريق العمل حسب طبيعة العمل

\begin{tabular}{|c|c|c|c|c|c|}
\hline \multicolumn{6}{|c|}{ حسب طبيعة العمل } \\
\hline و التخزين & الإتاحة & العمليات & السحب & الدوريات & الدوريات \\
\hline 1 & $r$ & $r$. & $r$ & 1 & $r$ \\
\hline \multicolumn{5}{|c|}{ r. } & الإجمالح \\
\hline
\end{tabular}

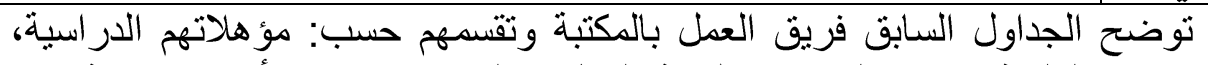

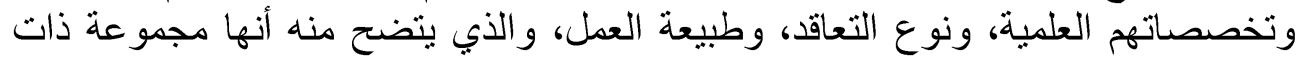

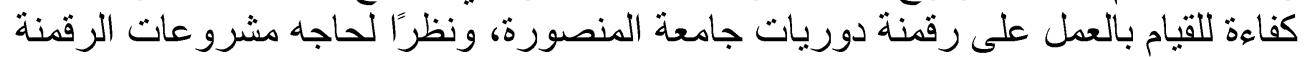

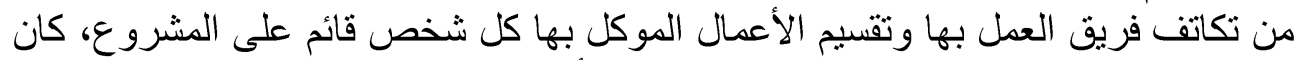

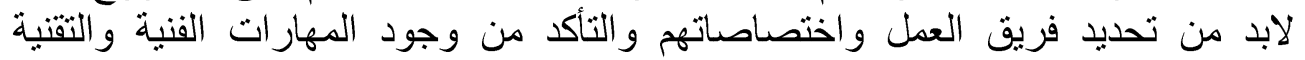

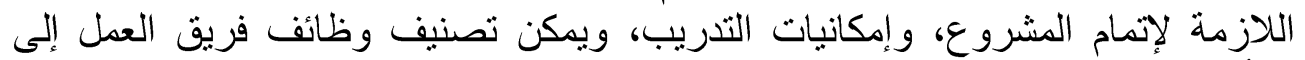
مائتي : يتكون الجهاز الإداري للمشروع من:

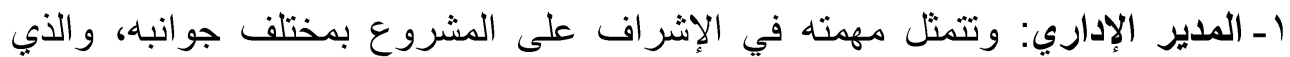

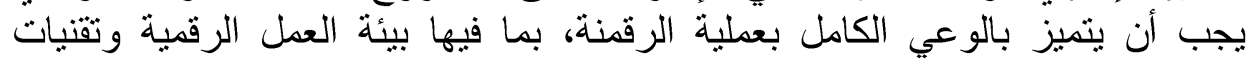

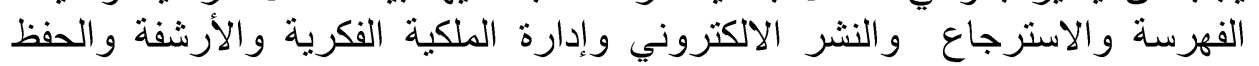

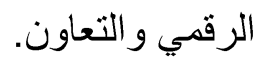

rـ المدير القني: وتتمثل وظيفته في إدارة العمل القني للمشروع المتعلق برقمنة الدوريات

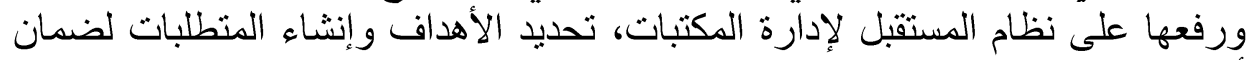

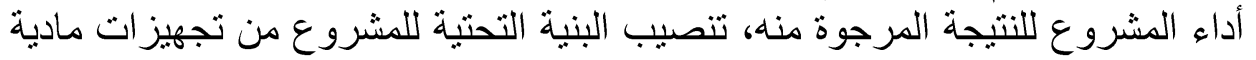

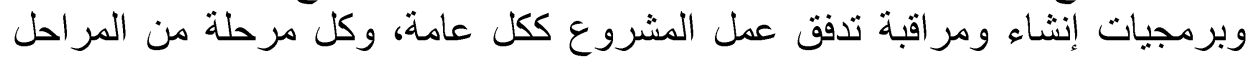

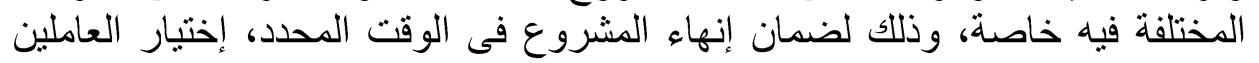

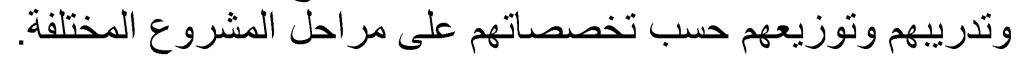


rـ الموظفون: وهم الذين يقومون بعملية رقمنة الدوريات ورفعها على نظام المستقبل،

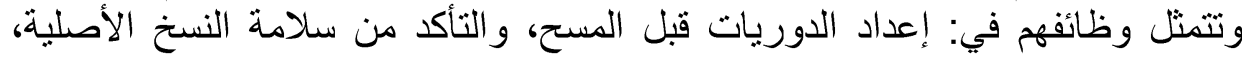

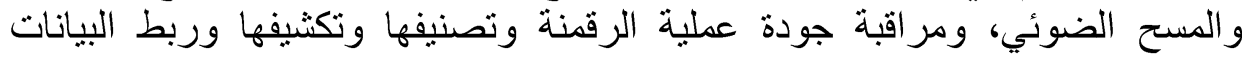

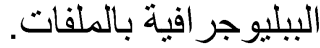

ـ ـ الثئون المالية: تهنم بكل ما يخص المسائلئل المالية و الحسابية، ويتمثل دور ها في تمويل

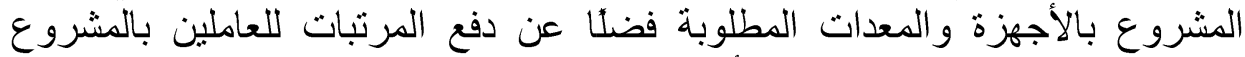
سو اء المعينون منهم على المشروع أو غير المعات المعينين بمقابل مكافآت مالية.

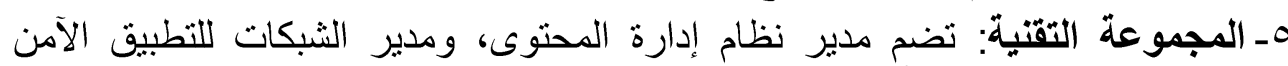

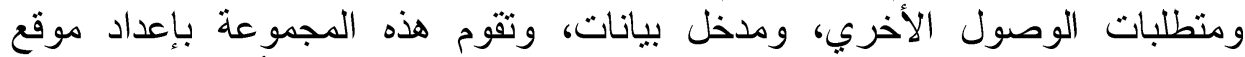

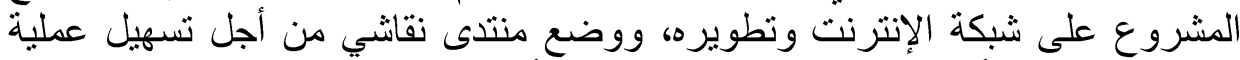

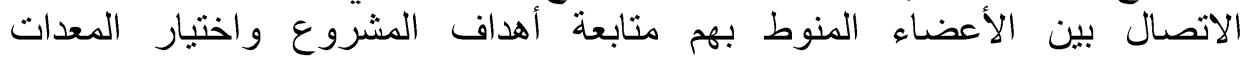
و البرمجيات والتحقق من هوية المستقيد.

جدول (^) الموارد البثرية

\begin{tabular}{|c|c|c|c|}
\hline$y$ & نعم & الموارد البشرية & عدد البنود \\
\hline & $\sqrt{ }$ & فيتم عملية الرقمنة وظيفة كل موظف & .1 \\
\hline & $\sqrt{ }$ & يوجد تدريب بصورة مستمرة & $r$ \\
\hline$\sqrt{ }$ & & يلإدم اختيار مسئؤلين مؤهلين علمبا & $r$ \\
\hline & $\sqrt{ }$ & التكثنيف اختيار موظفين مؤهلين لعملية العنية & . \\
\hline$\sqrt{ }$ & & الضوجدئي مسئولون عن جودة المسح & 0 \\
\hline & $\sqrt{ }$ & التسجيلات مسئولون عن مراقبة جودة & .7 \\
\hline
\end{tabular}

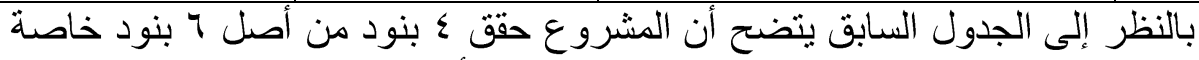

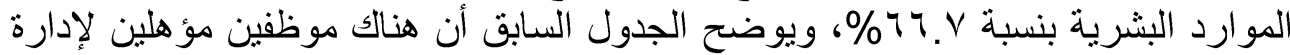

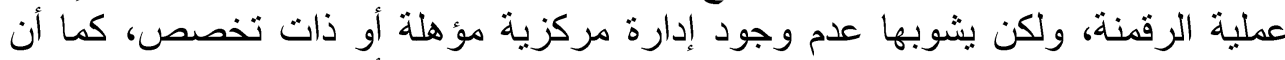

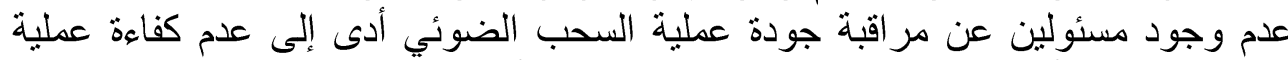

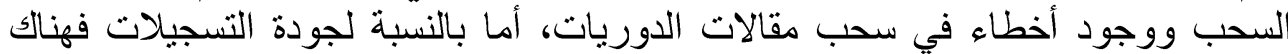

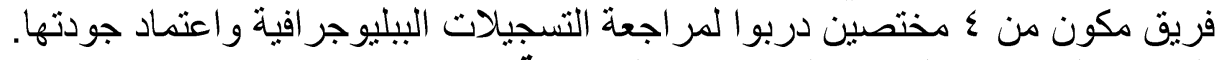

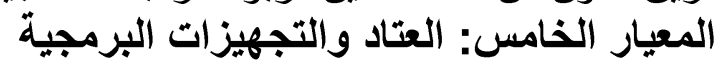

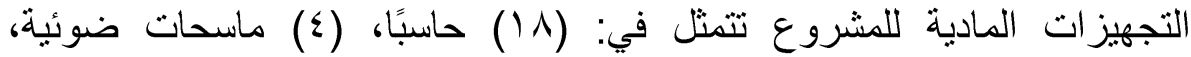

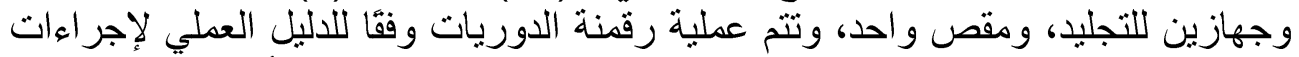

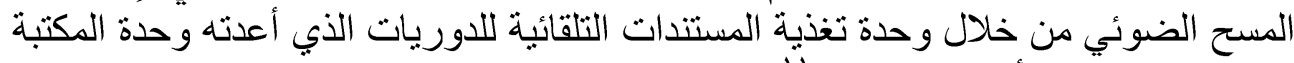

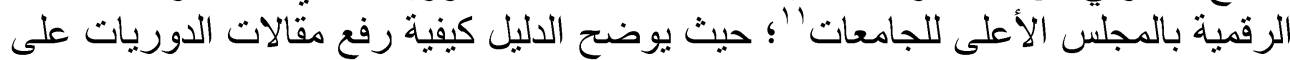

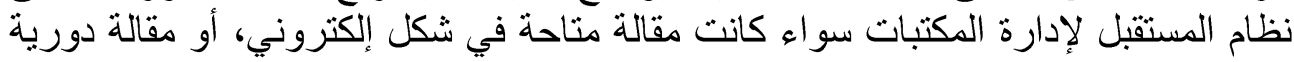
في الثكل الورقي وليس لها نظير إلكتروني. 


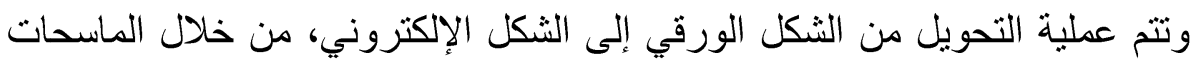

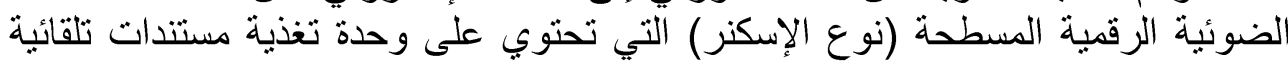

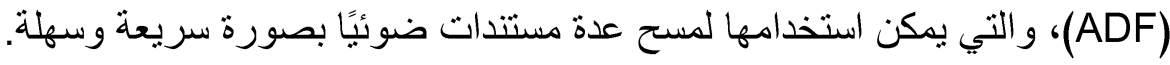

\section{(مقص) ثقطبح)

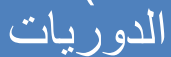

$$
\begin{aligned}
& \text { السحب الضوئي } \\
& \text { Scaning }
\end{aligned}
$$

\section{التجليد}

$$
\text { شكل رقم (1) مر احل السحب }
$$

\section{تجهيزات المسح الضوئي :}

HP Scanjet 5590 قاعه المسح الضوئي: وتحتوي المكتبة على ماسح من نوع التي تحتوي على وحدة تغذية مستندات تلقائية (ADF)، و التي يمكن استخدامها لمسح عدة

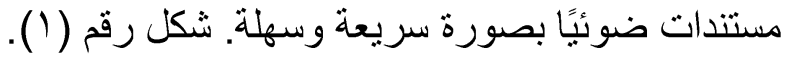
وتم إضافة ع ماسحات حديثة وتخلصوا من الماسحات القديمة، وهي من نوع

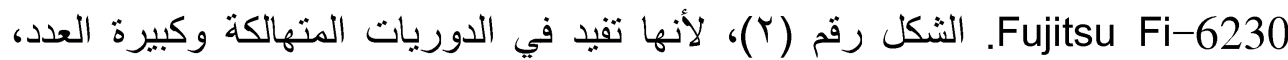
وتساعد على الحد من مخاطر إتلاف الورق أثناء عملية المسح الضونئي بالإضافة إلى تلى تغلبها على مثاكل تقوس الصفحات بسبب التجليد؛ مما يوفر مزيدًا من المجهود التهاء في مرحلة ضبط

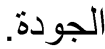
يوضح الثكلان ا و ب أنواع الماسحات الضوئية فى المكتبة المركزية بجامعة

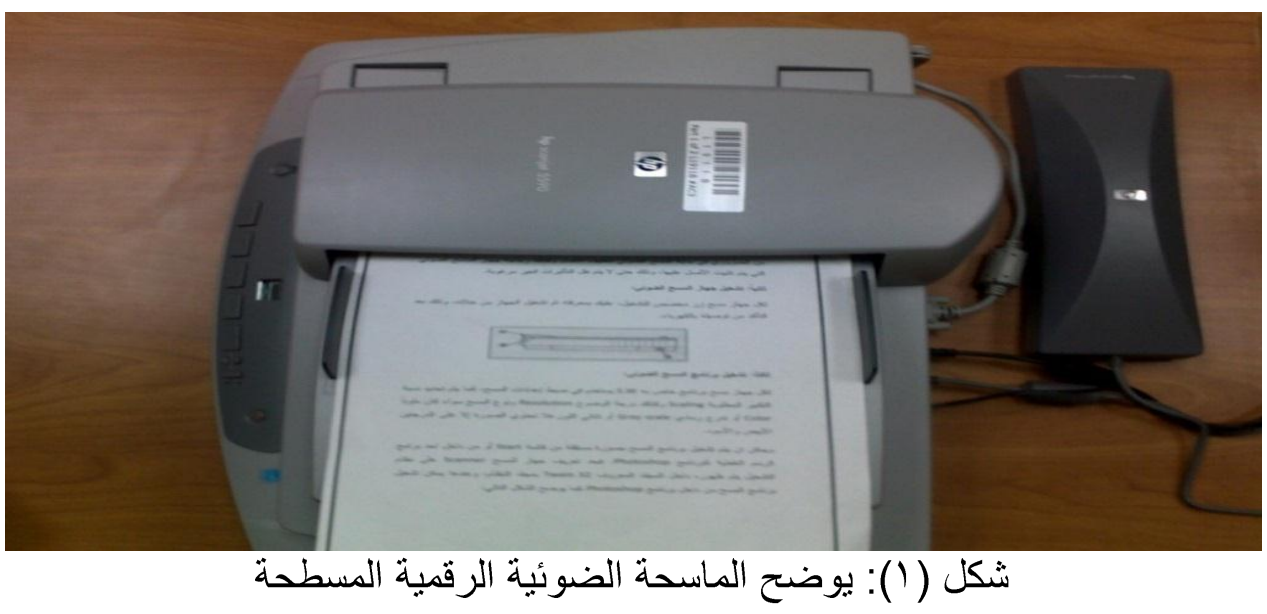




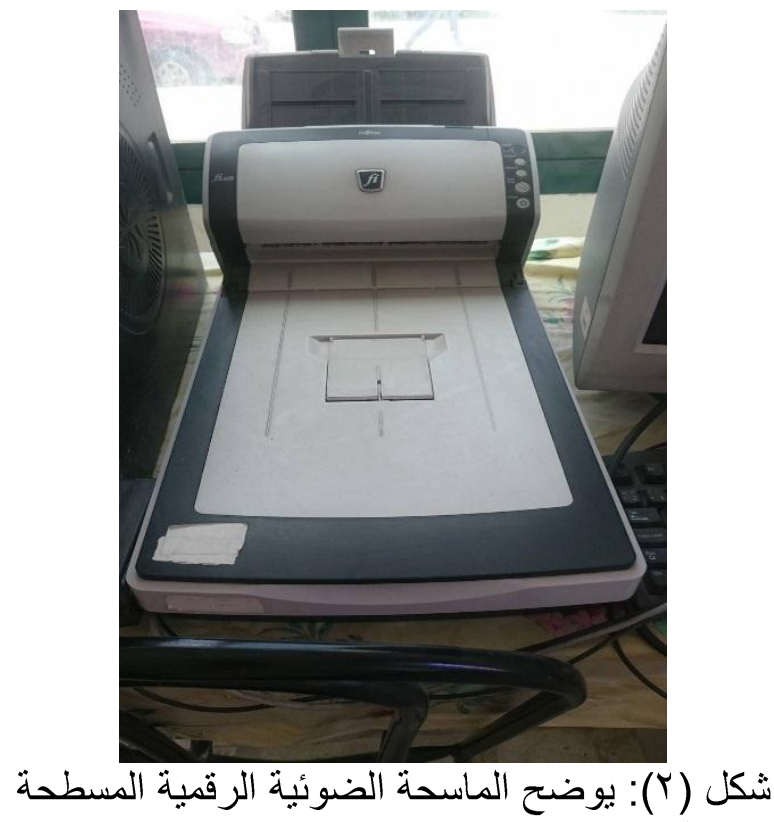

تجهيزات شبكة الاتصال

تتكون من ارتباط سريع سلكي ولاسلكي بشبكة الإنترنت من خلال شبكة جامعة فيكة

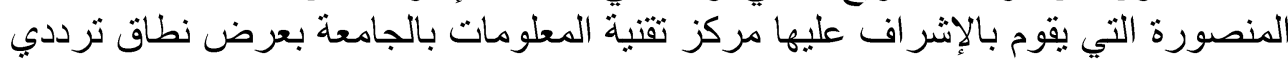

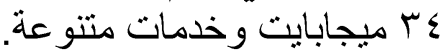

النظم والبرمجيات

نظام التشغيل "operating system وقامت جامعة المنصورة باستخدام نظام windows واستعين بمجموعة من البرمجيات التي تستخدم للإدارة أنشطة عملية في

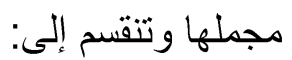
ا ـ برمجيات التقاط الصور: وتعمل تلك البرمجيات كأجهزة خاصة بالمسح الضوئي وفقا

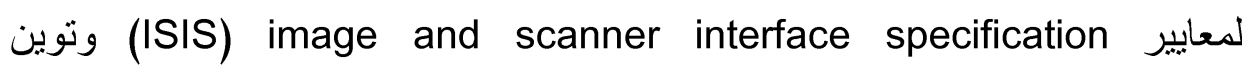
و هي واجهة معيارية موحدة لالتقاط الوثائق باستخدام الماسحات الضوئية،

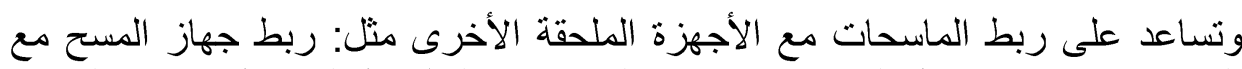

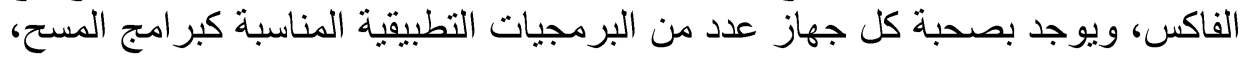

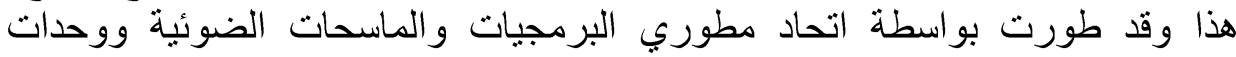
التصوير و الكامير ات الرقمية وبرنامج الحأسب.

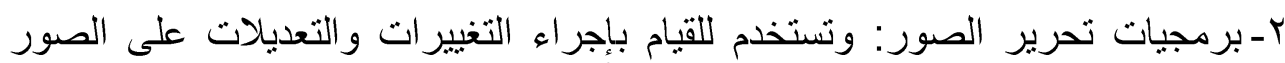

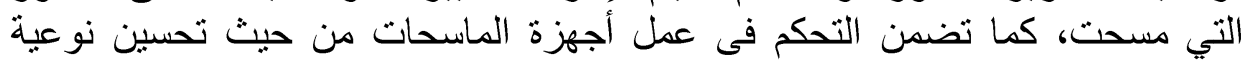

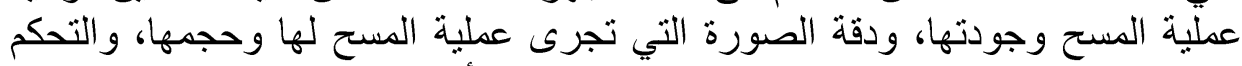

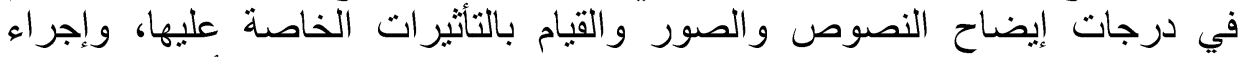
التغيرات والتعديلات على الصورة التي مسحت كحجم الصورة، وأبعادها ومقدار وضوحها. بـ برمجيات التعرف الضوئي على الحروف: و التي تستخدم في حالة الرغبة في تحويل

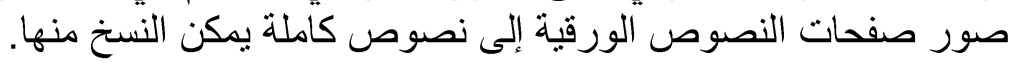


ع - برمجيات إدارة الكيانات الرقمية: والتي تسمح بإدارة وتوصيل الدوريات والميتاداتا المرتبطة بها.

كما استعين بنظام المستقبل لإدرة المكتبات التي كان لمركز تقنية المعلومات الدور

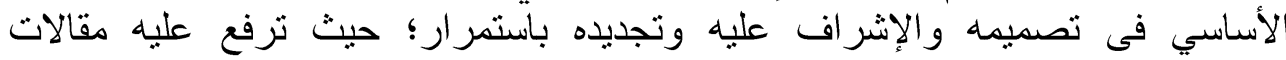

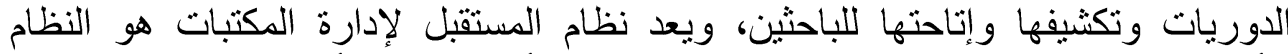

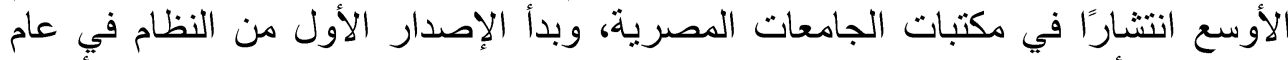

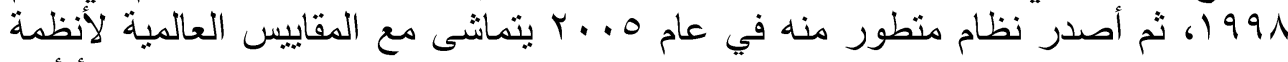

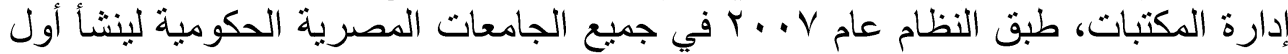

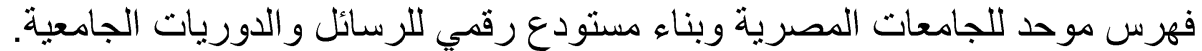

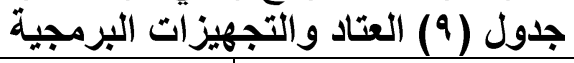

\begin{tabular}{|c|c|c|c|}
\hline$y$ & نعم & العتاد و التجهيز ات البرمجية & عدد البنود \\
\hline & $\sqrt{ }$ & 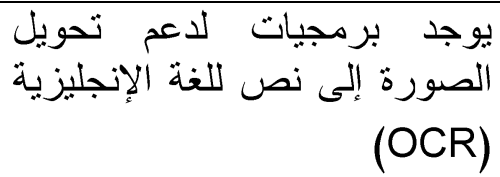 & .1 \\
\hline \multirow[t]{3}{*}{$\sqrt{ }$} & & الصوجد برة إلى نص للغيات ل لدعم العربية & $r$ \\
\hline & $\sqrt{ }$ & 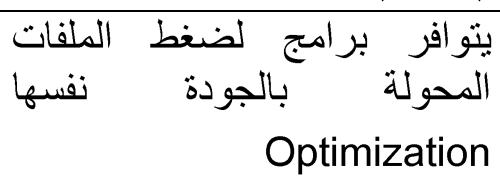 & r \\
\hline & $\sqrt{ }$ & $\begin{array}{r}\text { تتو افر انظمة لتحويل الصورة الى } \\
\text { PDF }\end{array}$ & $\varepsilon$ \\
\hline \multirow[t]{5}{*}{$\sqrt{ }$} & & يتتم الاعتماد على المصدر انظمة التشغيل & 0 \\
\hline & $\sqrt{ }$ & يعتمد النظام على محرر HTML & .7 \\
\hline & $\sqrt{ }$ & 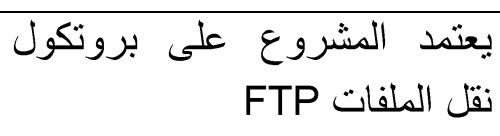 & $v^{V}$ \\
\hline & $\sqrt{ }$ & أجهزة العميل بدو الخادم أنظمة تشغيل & $\wedge$ \\
\hline & $\sqrt{ }$ & تتوفر مخرجات الويب المعروفةع على & .9 \\
\hline$\sqrt{ }$ & & الحاسب لكل مدد مناسب من أجهزة & .1 \\
\hline$\sqrt{ }$ & & عد حجم الماسحات الضوئية بتناسب & .11 \\
\hline
\end{tabular}




\begin{tabular}{|c|c|c|c|}
\hline$\left(Y, I V_{0}\right.$ & & \multicolumn{2}{|c|}{ حوليات آداب عين شمس } \\
\hline$\sqrt{ }$ & & بتناسب مع حجمات الدوريات و التجليد & $.1 \%$ \\
\hline & $\sqrt{ }$ & مخرجات المشروع ع يتناسب مع & r \\
\hline & $\sqrt{ }$ & يوجد خادم لحفظ نسخ احتياطية & $.1 \varepsilon$ \\
\hline & $\sqrt{ }$ & يتو افر لموظفيلات بالإنترنت لكل & .10 \\
\hline
\end{tabular}

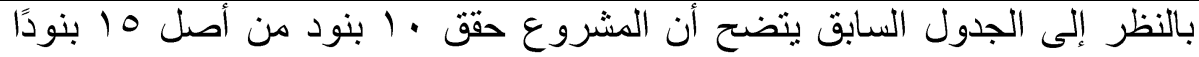

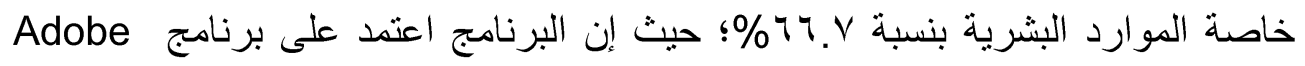
9 و الذي يسمح بعمل كل من Oprobat 9 ال OCR لا يدعم اللغة العربية فقى حالة المقالات باللغة العربية يكتفي المشروع بعمل بعل Optimization

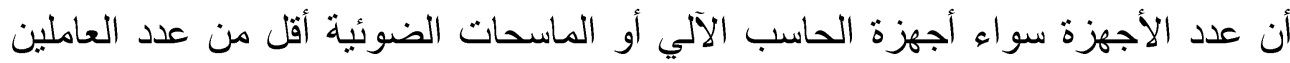

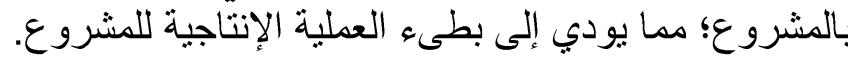

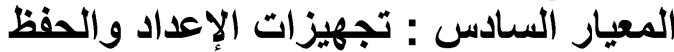

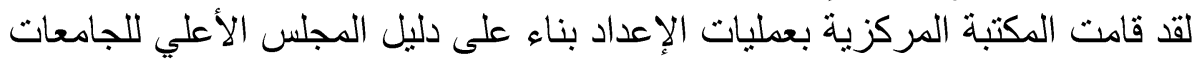

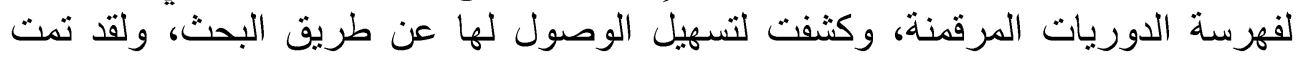
عملية الرقمنة على عدد مر احل تثمثل في: المرحلة الأولى المعلى

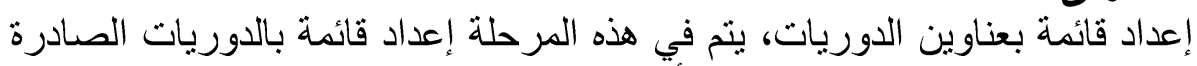

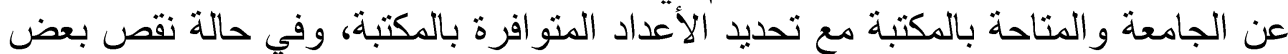

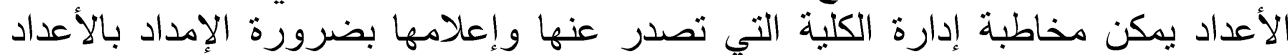

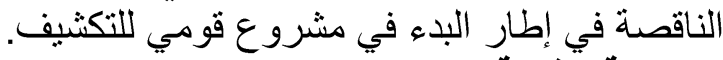
المرحلة الثثانية إرسال الدوريات إلى غرفة تقطيع الدوريات الورقية. المرحلة الثالثة سحب الدوريات التي قطعت للسحب بالإسكنر.

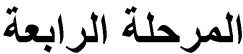

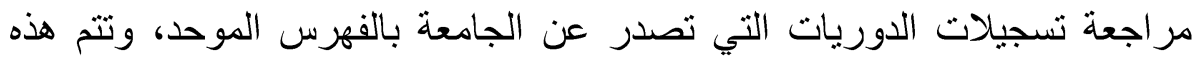

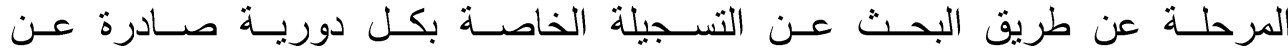

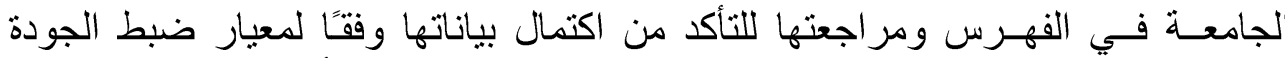

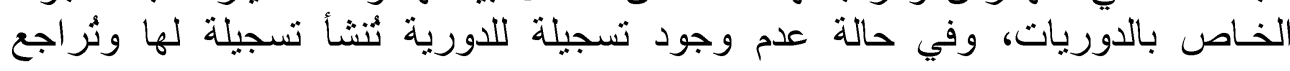

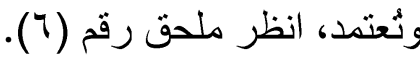

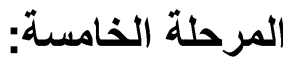

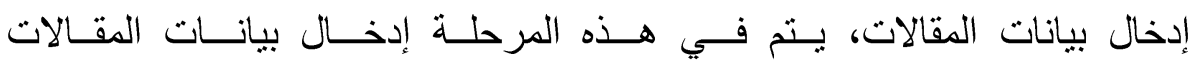

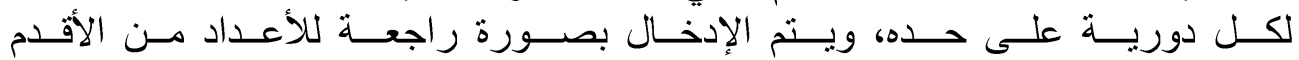




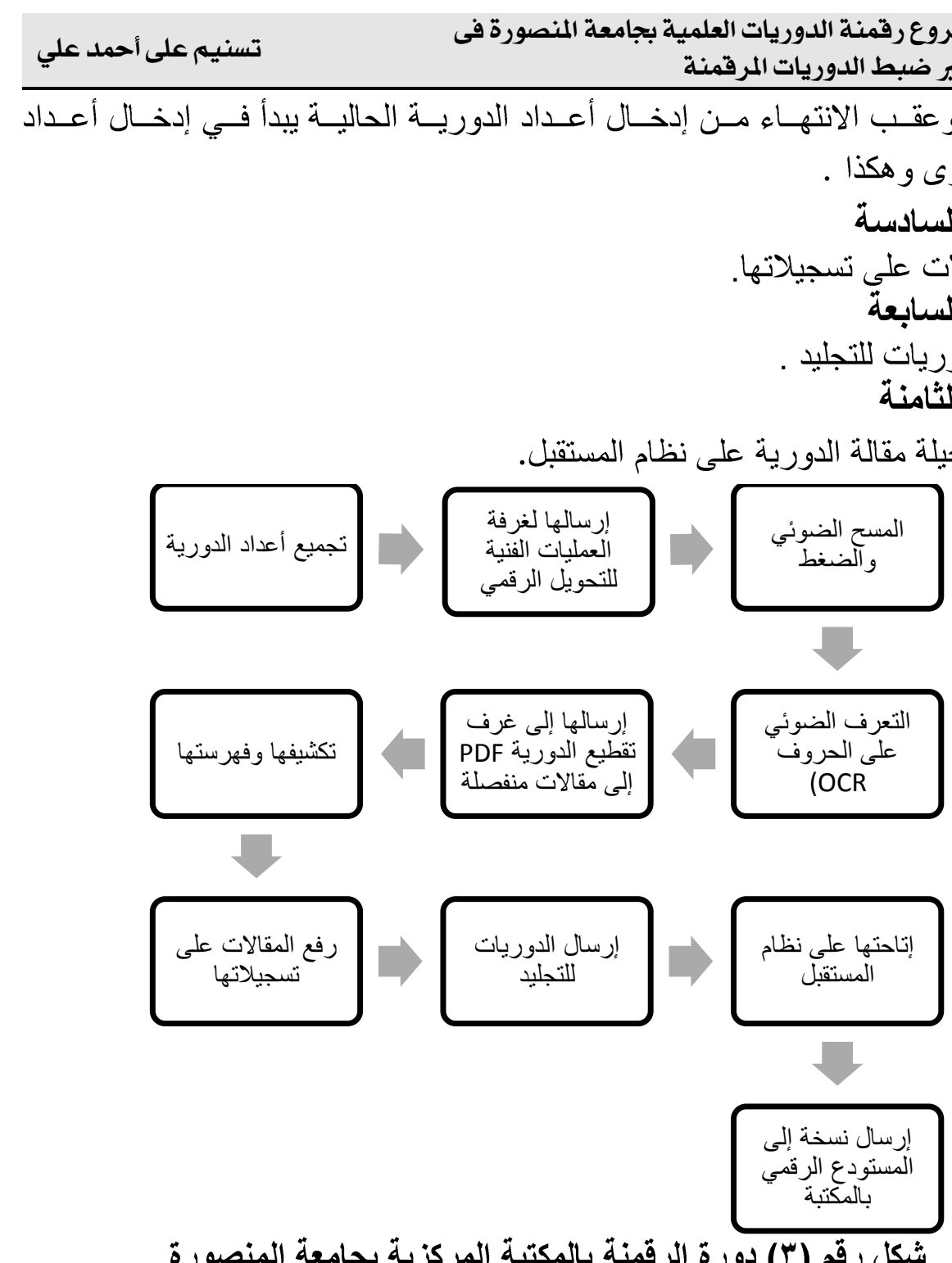

\section{المحتوى الذي رُقمن في فترة الدراسة الإنة}

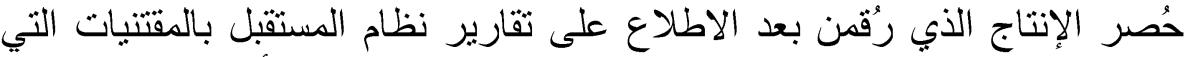

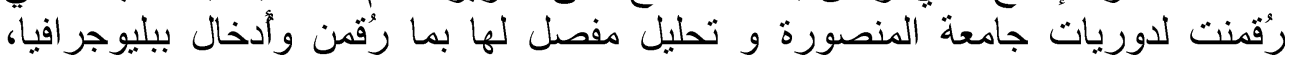

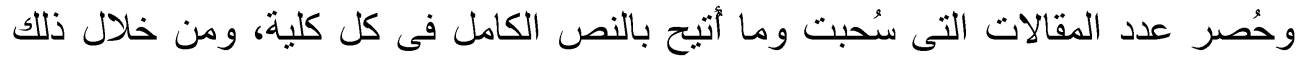

\section{جدول (9) بيان تفصيلبي لما رُقمن بجامعة المنصورة} الحصر يتضح ما يلى :

\begin{tabular}{|c|c|c|c|c|c|}
\hline ذالت الآصاتل & المبالات & مقالاتها & بالصامدورة & الدوريات & رقم \\
\hline $99 \wedge \vee$ & $\mid r \leq 1 \wedge$ & $|r T A|$ & كلية & المجلة العلوم الزراعية جامعة & 1 \\
\hline
\end{tabular}




\begin{tabular}{|c|c|c|c|c|c|}
\hline$(r \cdot) V_{u}$ & ع) & & & ب عين شمس & 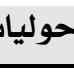 \\
\hline VIr & $V \leqslant 9$ & $V \leqslant 9$ & كلية & مجلة الإتتاج النباتي & r \\
\hline$\varepsilon r$. & $0 . \Sigma$ & $0 . \varepsilon$ & كلية الزراعة & مجلة الزراعية علوم التربة والهندسة & r \\
\hline$\varepsilon \vee \cdot$ & Tra & 711 & - كلية & الاجتماعية الاقتصاد الزراعي والعلوم & $\varepsilon$ \\
\hline 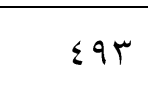 & OVT & $07 \mathrm{~V}$ & كلية & مجلة وقاية النبات و علم الأمر اض & 0 \\
\hline$r \varepsilon$ & Y74 & Yฯ & كلية الزراعة & مجلة الإنتاج الحيو اني و الدواجن & 7 \\
\hline rฯะ & $r \leqslant \wedge$ & tra & كلية الزراعة & الألبان علوم الاغذية ومنتجات & V \\
\hline 100 & $1 \wedge$. & 11. & كلية & و مجلة التكنولوجيا الكيوية $\quad$ الزراعية & $\wedge$ \\
\hline $15 \cdot 1$ & $1 \leqslant 0 \wedge$ & $1 \leqslant 0 \leqslant$ & كلية & التجارية المجلة المصريه & 9 \\
\hline $11 \leq$ & $V V \cdot$ & $V \leqslant \varepsilon$ & كلية & مجلة علوم البيئة & 1. \\
\hline 1. & $\wedge 7$ & rq & التلية & مجلة جامعة المنصورة للكيمياء & 11 \\
\hline · & 19 & 19 & العلية & $\begin{array}{rr}\text { الاحياء(بيولوجي) جامعة المنصورة لعلم } \\
\end{array}$ & Ir \\
\hline 790 & V०q & YOV & كلية & المجلة العلدية لكلية الآداب & 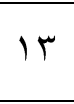 \\
\hline$r \cdot \varepsilon$ & $\sum V 1$ & $\{7)$ & كلية & مجلة المنصورة للعلوم الصيدلية & $1 \leq$ \\
\hline $111 \mathrm{~V}$ & ITHA & ITrA & كلبة & المنصورة العلمية $\quad$ لكلية تربية & 10 \\
\hline Tos & $\leqslant 99$ & \&AY & كلية & و الاقتصادية البحوث $\quad$ القانونية & 17 \\
\hline $10 r 9$ & $17 \leqslant 1$ & $17 \leqslant V$ & الهنية & المجلة الهندسية لجامعة المنصورة & IV \\
\hline 719 & 711 & 711 & كلية التربية & مجلة بحوث التربية النوعية & 11 \\
\hline 174 & $17 \varepsilon$ & $17 \varepsilon$ & التلية & والرياضة العلمية لعلوم التربية البدنية & 19 \\
\hline Tr. & Tr. & rr. & كلية & $\begin{array}{l}\text { Bulletin of } \begin{array}{r}\text { Egyptian } \\
\text { society for physiological } \\
\text { sciences }\end{array} \\
\end{array}$ & $r$. \\
\hline
\end{tabular}




\begin{tabular}{|c|c|c|c|c|c|}
\hline \multicolumn{3}{|c|}{ تسنيه على أحمد علي } & \multicolumn{3}{|c|}{ ضقييم مشروع رقيط الدوريات المريات العلمية بجامعة المنصورة فى } \\
\hline r & 104 & זי & & Mansoura science bulletin & r) \\
\hline 149 & $1 \times 9$ & IVA & |أطفال & الطفلة المنصورة لرعاية وتتمية & rt \\
\hline v & 11 & $\wedge$ & ضلية & دورية كلية التمريض & rt \\
\hline rVT & $r \cdot r$ & $r \cdot 1$ & 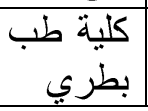 & دورية كلية طب بطري & $r \varepsilon$ \\
\hline $19 \vee \wedge 9$ & r $\leqslant 0$ Y & $r \leqslant Y T \leqslant$ & & & 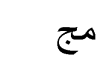 \\
\hline
\end{tabular}

حصر هذا الجدول كل الدوريات التى رُقمن فى جامعه المنصورة وعند تحليله

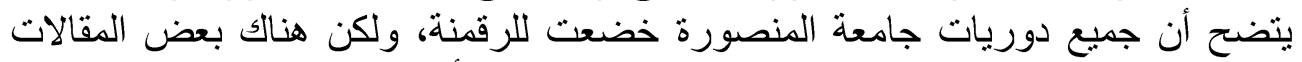

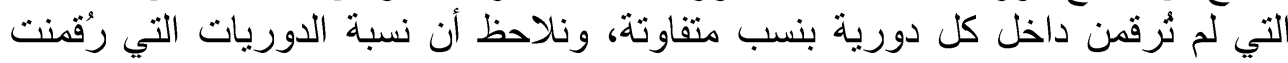

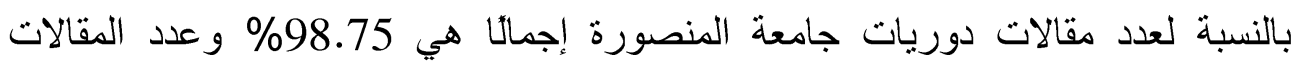

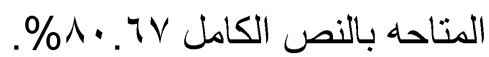

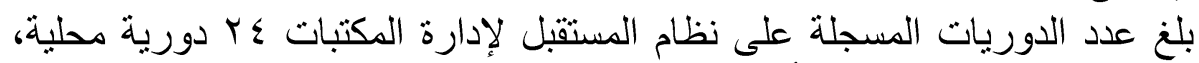

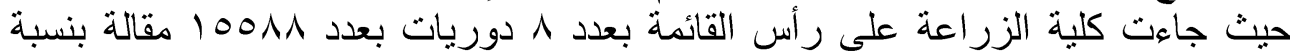

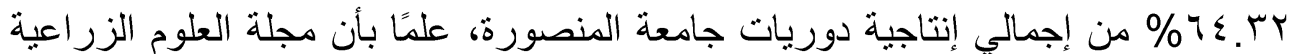

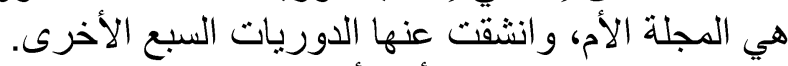

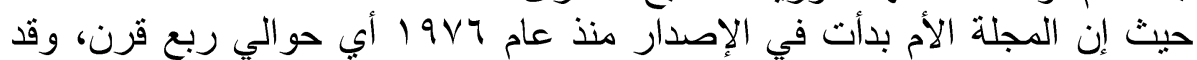

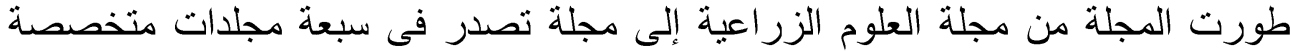

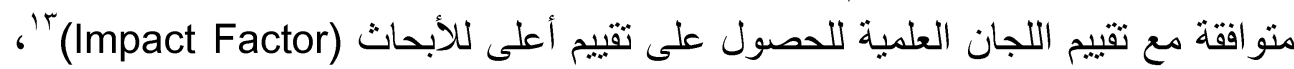

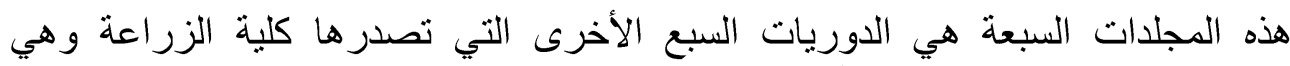
الإصدار ات الجديدة نفسها للمجلة.

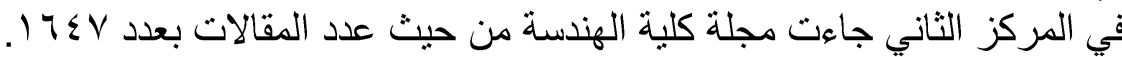

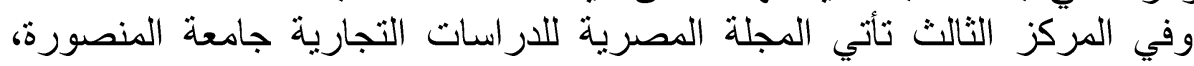

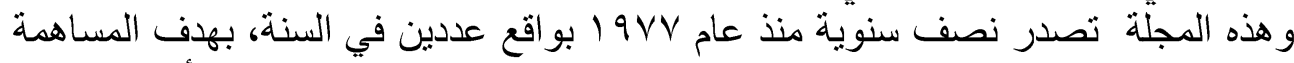

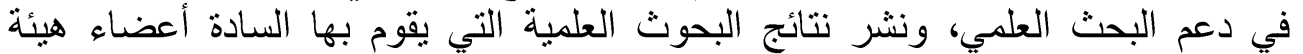

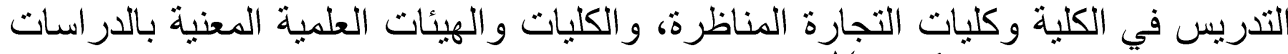

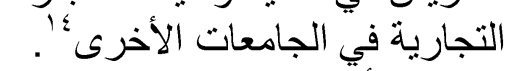
وتأتي في المركز الرابع مجلة كلية التربية فيما حققت الدوريات العشرون المتبقية

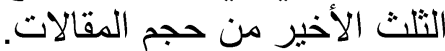
ويعد هذا التفاوت بين أعداد المقالات عامة داخل الدورية وأعداد المقالات المتاحة

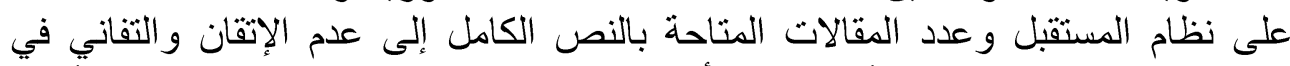

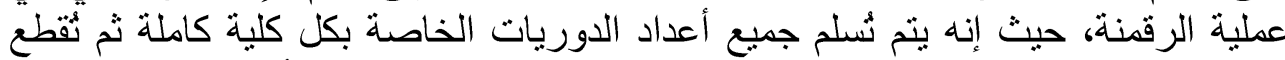

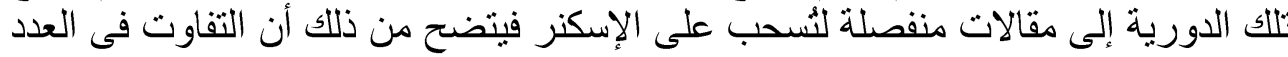
نتيجة الإهمال عند رفع بيانات المقالات المرقمنة و إدخالها. 


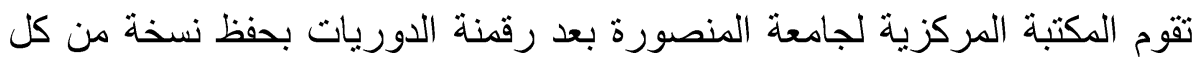

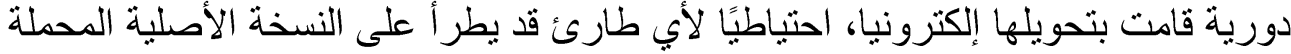

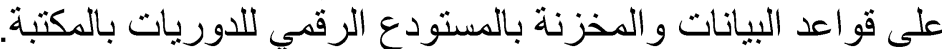

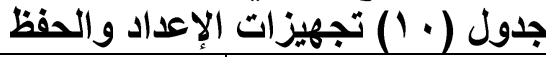

\begin{tabular}{|c|c|c|c|}
\hline$y$ & نعم & تجهيز ات الإعداد و الحفظ & عدد البنود \\
\hline & $\sqrt{ }$ & 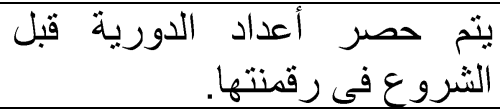 & .1 \\
\hline$\sqrt{ }$ & & الدتم عملية تقطيع النسخ لكل أعداد & $r$ \\
\hline \multirow[t]{2}{*}{$\sqrt{ }$} & & تَر اجع جودة عملية التقطيع. & $r$ \\
\hline & $\sqrt{ }$ & تسحب كل أعداد الدورية. & $\varepsilon$ \\
\hline \multirow[t]{3}{*}{$\sqrt{ }$} & & السحجد. مراجعة لجودة علية & 0 \\
\hline & $\sqrt{ }$ & 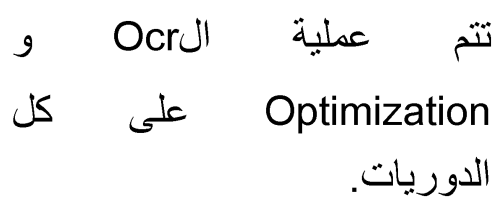 & .7 \\
\hline & $\sqrt{ }$ & كل مقالاتث الدوريات. والتكثيف والفرسة على & 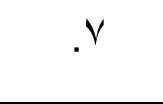 \\
\hline \multirow[t]{5}{*}{$\sqrt{ }$} & & رُقمنت كل مقالات الدورية. &.$\wedge$ \\
\hline & $\sqrt{ }$ & القتمبر التخزين واخلت مستوع المشى المدى على & .9 \\
\hline & $\sqrt{ }$ & الطّ التخزين داخل مستودع المشرى على المدى. & 1. \\
\hline & $\sqrt{ }$ & الكيانات الرقدى المية المحولة. لأقصى ل لحفظ & .11 \\
\hline & $\sqrt{ }$ & خادجد مستقل عن خادم المشروع. رُقمن فى & .14 \\
\hline \multirow[t]{4}{*}{$\sqrt{ }$} & & المستقبل. الحفظ مباشرة على نظام & .11 \\
\hline & $\sqrt{ }$ & 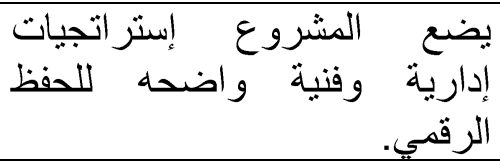 & $.1 \leqslant$ \\
\hline & $\sqrt{ }$ & 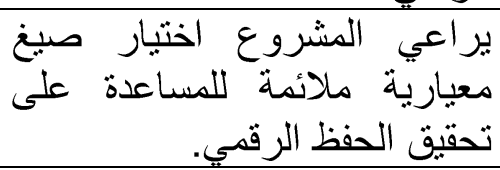 & .10 \\
\hline & $\sqrt{ }$ & يتم الحفظ الرقمي بكفاءة تتلاعم & .17 \\
\hline
\end{tabular}




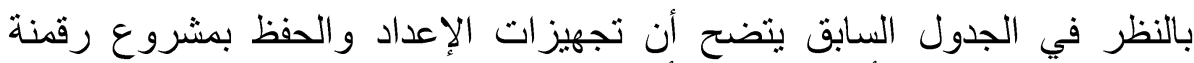

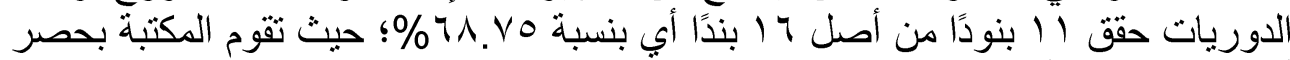

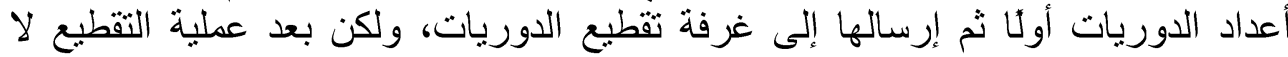

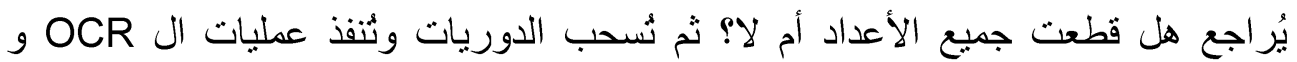
Optimization تقوم المكتبة المركزية بتوفير تخزين وحفظ للمواد المرقمنة داخل المستودع في الخادم

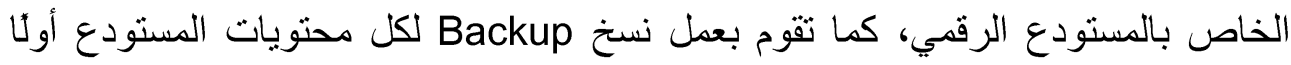

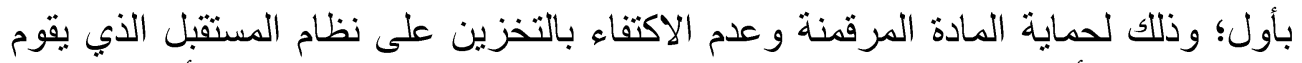

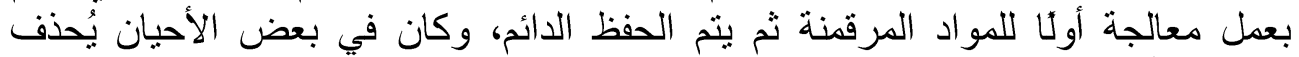

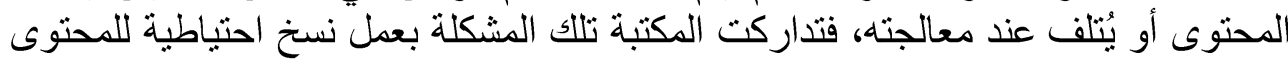

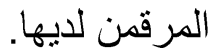
المعيار السابع: الضبط البيليوجرافي للاوريات لضمان حصر وجمع كل أنوأع البيانات الوصنية الوريات المتعلقة بالمادة خلال عملية

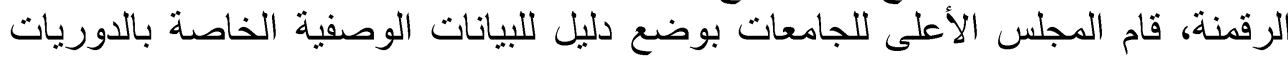

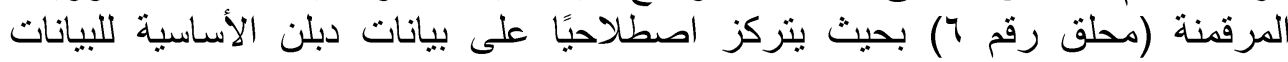
الوصفية. ولكي تَفهرس تسجيلة دورية يتم التالى:

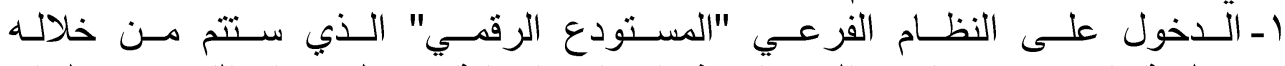

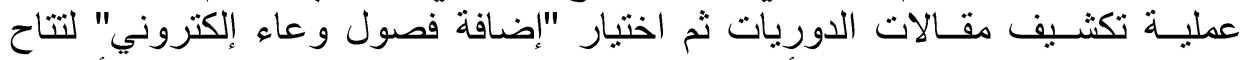

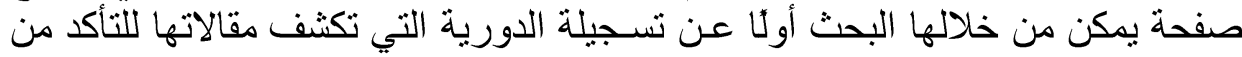

وجود تسجيلتها في الفهرس الموحد وفي حالة عدم وجودها تنشأ تسجيلة لها.

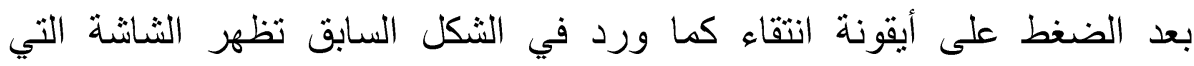

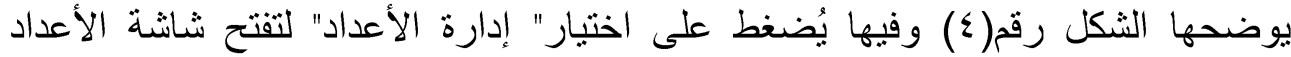

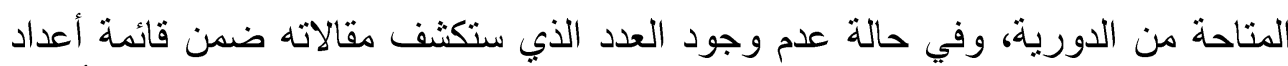

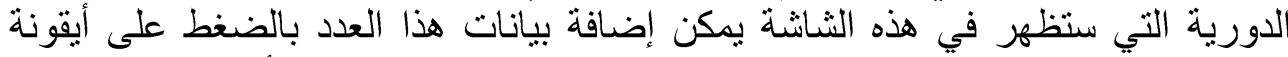

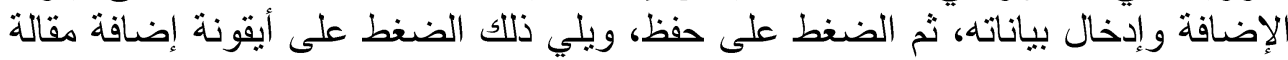

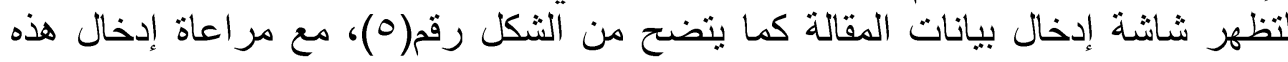
البيانات وفقا لمعيار ضبط جودة تسجيلات مقالات الدوريات. 


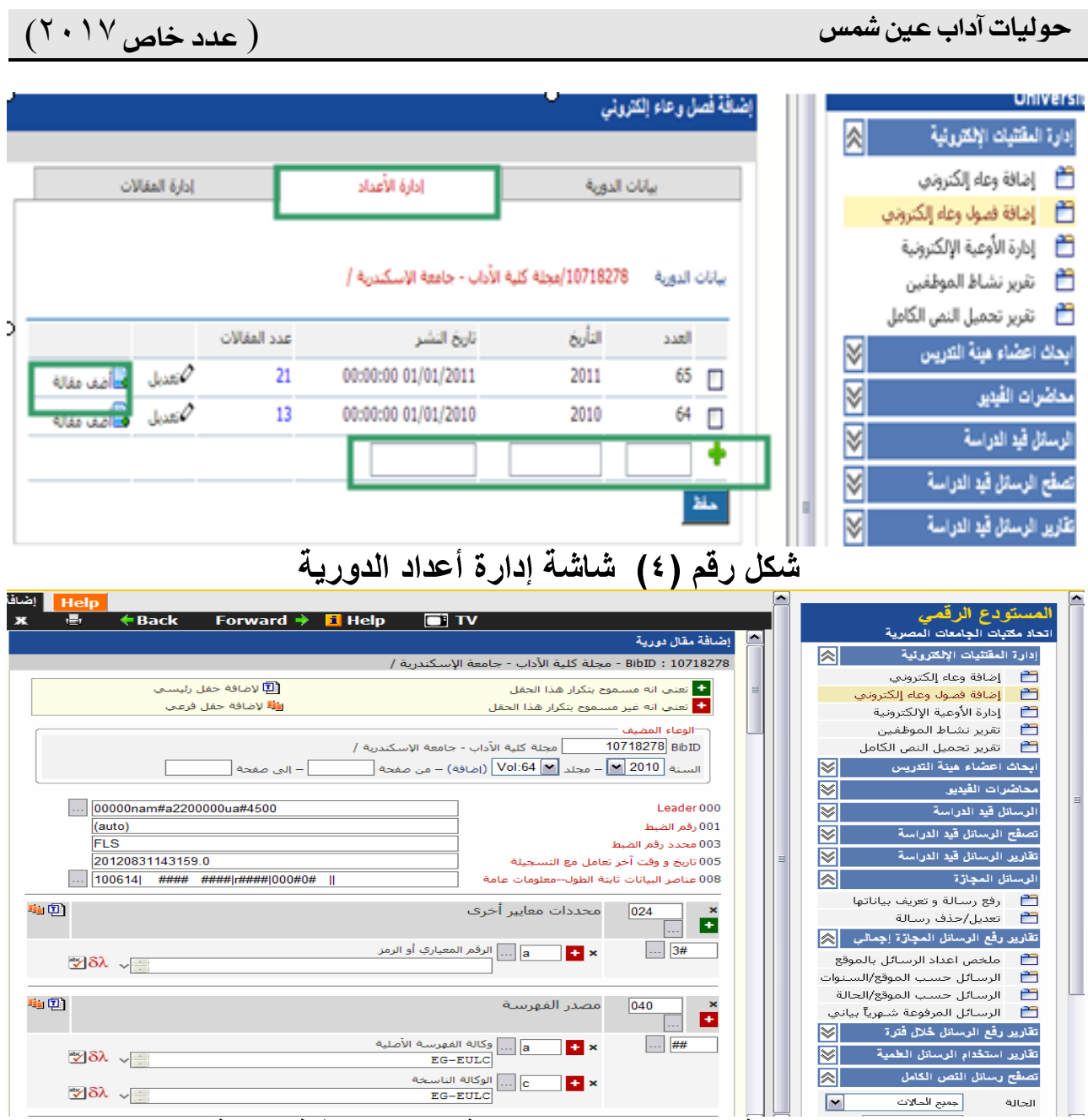

شكل رقم (0) شاشة إدخال بيانات التسجيلة البيليوجرافية لمقالة الدوري جدول (Y I) الضبط البيليوجرافي للاوريات

\begin{tabular}{|c|c|c|c|}
\hline$y$ & نعم & الضبط الببليوجر افي للدوريات & عدد البنود \\
\hline & $\sqrt{ }$ & 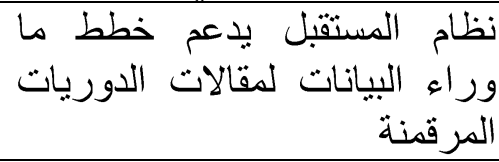 & 1 \\
\hline & $\sqrt{ }$ & هل تل تستخدم قواعد فهرسة & $r$ \\
\hline$\sqrt{ }$ & & تلحاسب الآلى قو اعد فهرسة ملفات & $r$ \\
\hline & $\sqrt{ }$ & يعتمد النظام على قواعد مارك 21 اللفهرسة & $\varepsilon$ \\
\hline & $\sqrt{ }$ & 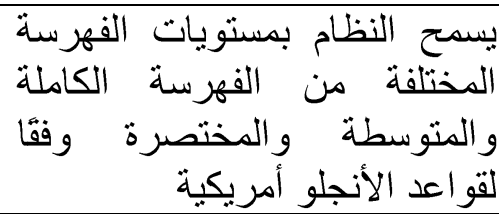 & 0 \\
\hline
\end{tabular}




\begin{tabular}{|c|c|c|c|}
\hline \multicolumn{2}{|c|}{ تسنيم على أحمد علي } & \multicolumn{2}{|c|}{ ضقييم مشروع رقمنة الدوريات العلمية بجامعة المنصورة فى المبات } \\
\hline & $\sqrt{ }$ & لغة في عناصر النظام باستخدام اكثر من & .7 \\
\hline & $\sqrt{ }$ & الميتاداتا النظتخدمة بالتوسع فى حقول & V \\
\hline & $\sqrt{ }$ & إدخالها النظام تعديل التسجيلات بعد &.$\wedge$ \\
\hline \multirow[t]{3}{*}{$\sqrt{ }$} & & يتيح النظام التعديل الثنامل لحقل التسجيلة لمجموعة من & .9 \\
\hline & $\sqrt{ }$ & تستخدم خطة مارك للتصنيف & .1 . \\
\hline & $\sqrt{ }$ & يتيح النظام تسجيل أكثر من رأس التسبل & .11 \\
\hline$\sqrt{ }$ & & الأليح للمقالات النظام خدمة الاستخلاص & .14 \\
\hline$\sqrt{ }$ & & تكثنف محتويات المقالات ألياً & .14 \\
\hline \multirow[t]{3}{*}{$\sqrt{ }$} & & تكثنف من خلالدورية التي رقده استمار ات & $.1 \varepsilon$ \\
\hline & $\sqrt{ }$ & للاطوفلاع النظام حقل الإكتروني على اللـقالة & .10 \\
\hline & $\sqrt{ }$ & 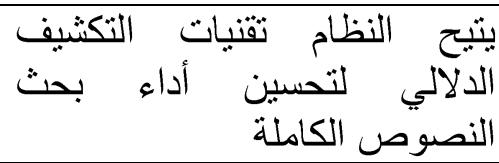 & .17 \\
\hline
\end{tabular}

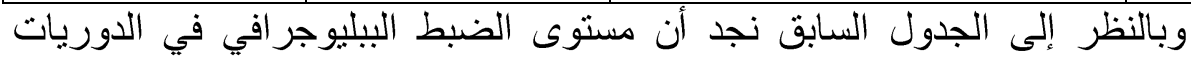

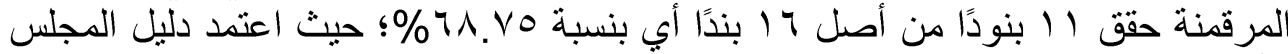

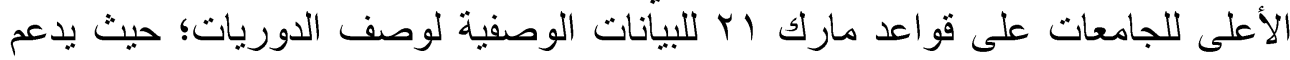

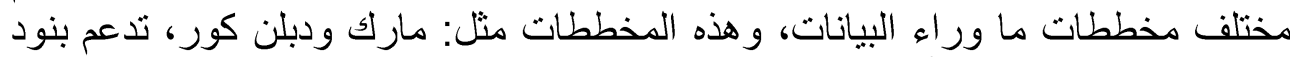

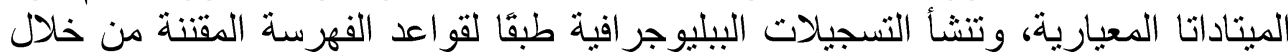

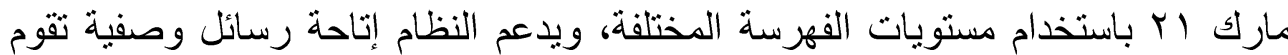

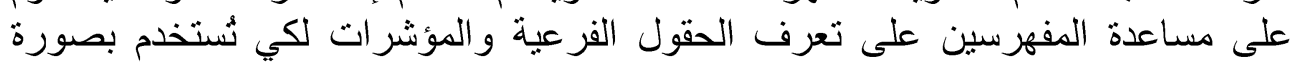

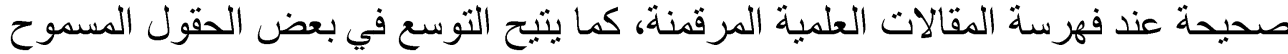
بتكرر ها مثل حقول رعوس الموضوعات، كما يتيح النظام الولوج إلى التى المقالات المرقئة

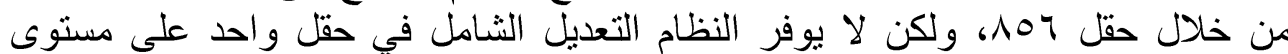

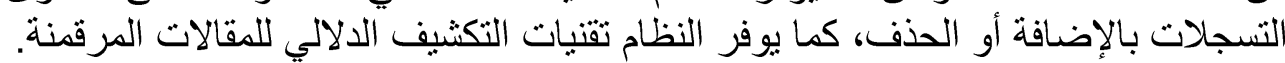

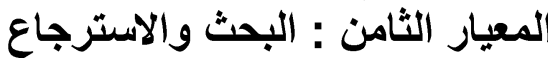

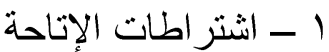

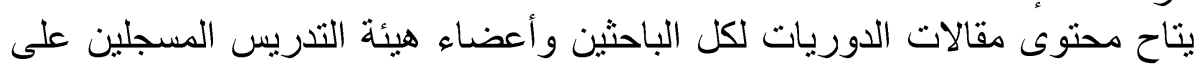

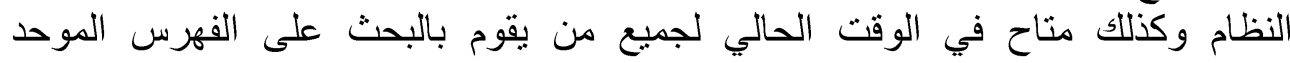


للجامعات المصرية بالاطلاع على المقالات، وكذلك تنزيلها. r - ب المستقبدون من الإتاحة

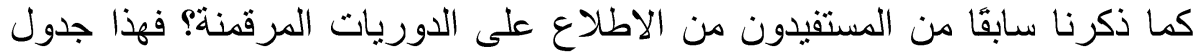

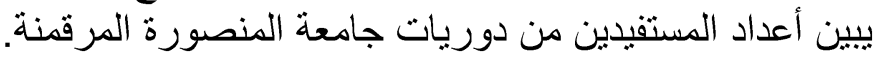

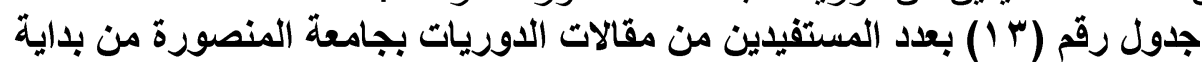

\begin{tabular}{|c|c|c|c|c|}
\hline المستقيدون من المستعيرين & خارج النظّنام من & بالجامعة & الاوريات & رقم \\
\hline 1178 & $1 \leqslant 9 \vee 7$ & كلية الزر اعة & الزجلة $\quad$ الزربة بجامعة & 1 \\
\hline$V \varepsilon$ & $19 . Y \varepsilon$ & كلية الزر اعة & مجلة $\quad$ النباتي & r \\
\hline$q \mu \cdot \varepsilon$ & 94.7 & كلية الزر اعة & و والهندسة علوم التزبة الزبة & $r$ \\
\hline $1 \cdot \lambda \wedge$ & 17910 & كلية الزر اعة & الزجلة $\quad$ الارجماعية و العلوم & $\varepsilon$ \\
\hline $7 \varepsilon$ & $I T V \cdot A$ & كلية الزر اعة & وعلة وقاية النبات الأمر اض & 0 \\
\hline V & $r v \cdot \varepsilon$ & كلية الزر اعة & الأغذية ومنتجات & 7 \\
\hline TV & 7707 & كلية الزر اعة & 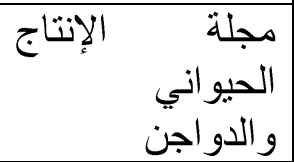 & V \\
\hline 10 & $\Gamma \leqslant \wedge \Lambda$ & كلية الزر اعة & 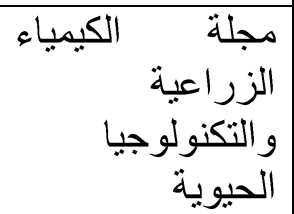 & $\wedge$ \\
\hline 10094 & - & كلية التجارة & للار اسلهات التجارية المصرية & 9 \\
\hline- & $r \varepsilon r$ & كلية العلوم & مجلة علوم البيئة & 1 . \\
\hline$r$ & - & كلية تمريض & مجلة $\quad$ المنصورة للكيمياء & 11 \\
\hline וYוTI & - & كلية الآداب & لكلبة الآدابلة العلمية & Ir \\
\hline$\varepsilon \varepsilon$ & - & كلية الصيدلة & للعلوم الصبدلة المنصورة & IT \\
\hline
\end{tabular}




\begin{tabular}{|c|c|c|c|c|}
\hline \multicolumn{2}{|c|}{ تسنيم على أحمد علي } & \multicolumn{3}{|c|}{ تقوء معايير ضروع رقمنة الدوريات المرقمينة العلمية بجامعة المنصورة فى } \\
\hline 9.77 & - & كلية التربية & الكلية $\quad$ المجلة $\quad$ العلمبية & $1 \varepsilon$ \\
\hline $107 \mathrm{~V}$ & - & كلية الحقوق & والقانونية $\quad$ البحوث & 10 \\
\hline 001 & - & كلية الهندسة & لجامعة المنصورة الهندسية & 17 \\
\hline or & - & كلية الطب البيطري & البيطرية & iv \\
\hline 919 & - & كلية رياض أطفال & لرجلة الرعاية $\quad$ ولتصورة & 11 \\
\hline oryo & - & كلية التربية النوعية & مجلة مبلة النو عبةث & 19 \\
\hline 779 & - & الرياضية $\quad$ التربية & 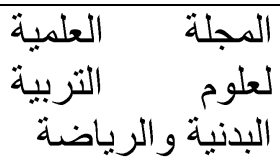 & $r \cdot$ \\
\hline$\varepsilon \wedge$ & YYO. & كلية الطب & لجامعة المنصورة الطبية & YI \\
\hline$\varepsilon \wedge \neg \leqslant 0$ & 11.09. & & & 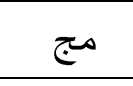 \\
\hline
\end{tabular}

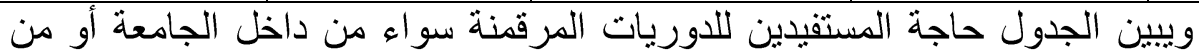

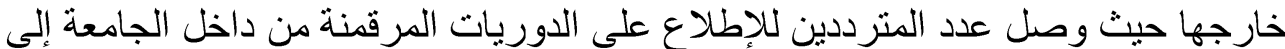

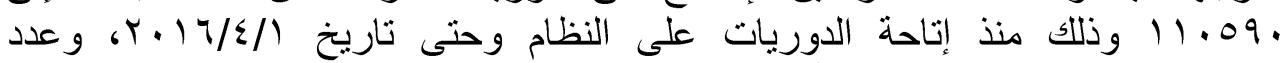

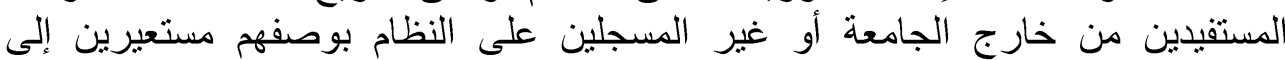

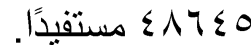

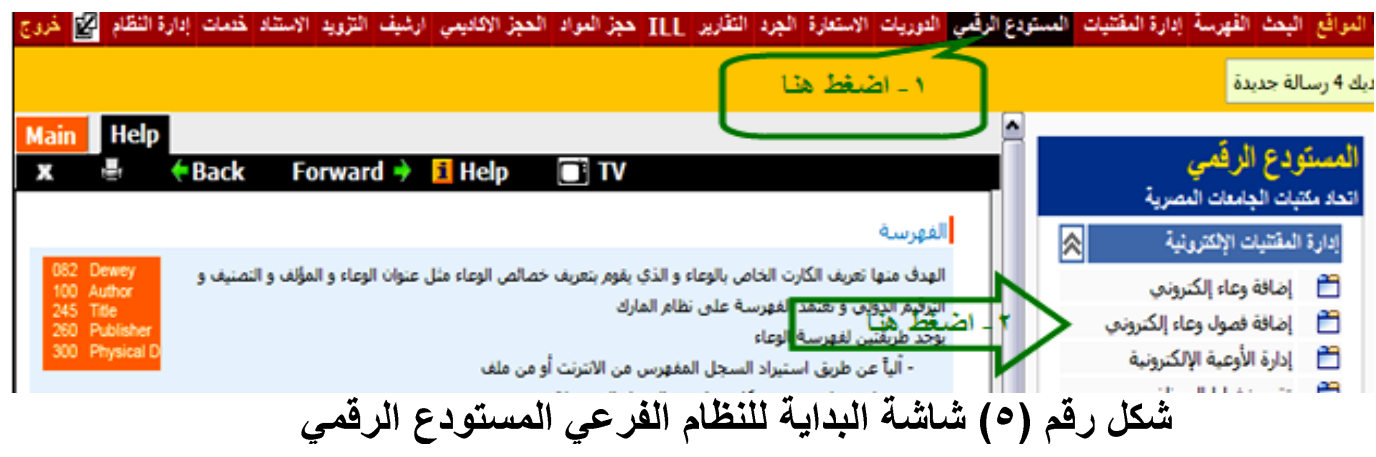


rـ البحث عن تسجيلة الدورية التي ستكثف ويمكن البحث عن الدورية بأكثر من عنصر

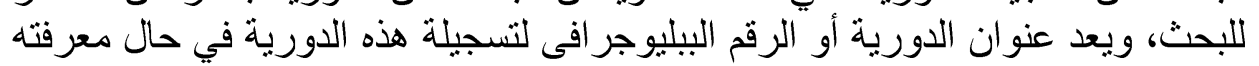
أبرز العناصر التي يمكن من خلالها البحث عن تسجيلة الدورية.

\section{国}
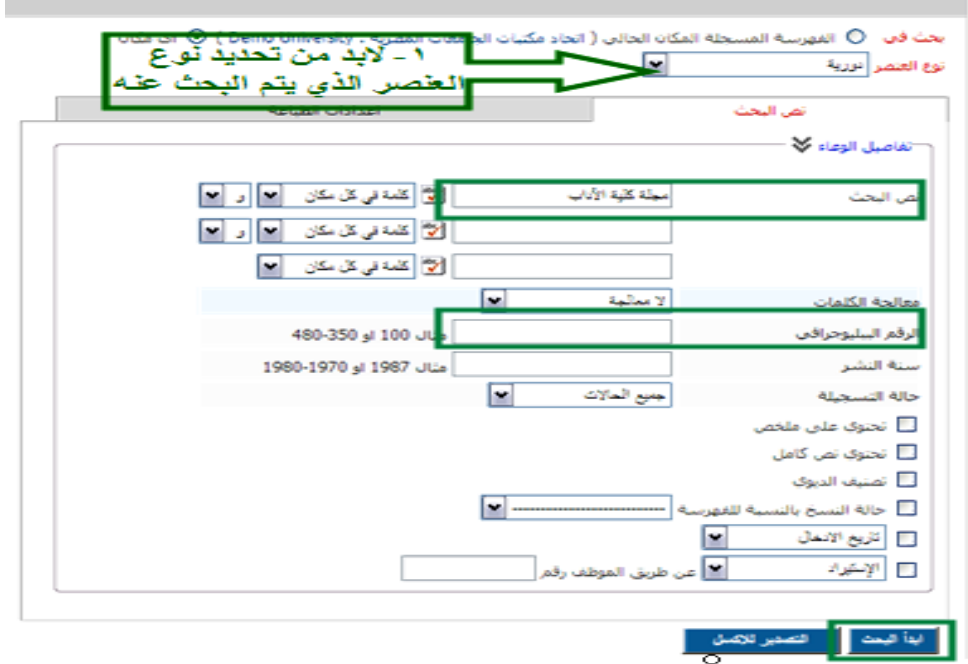

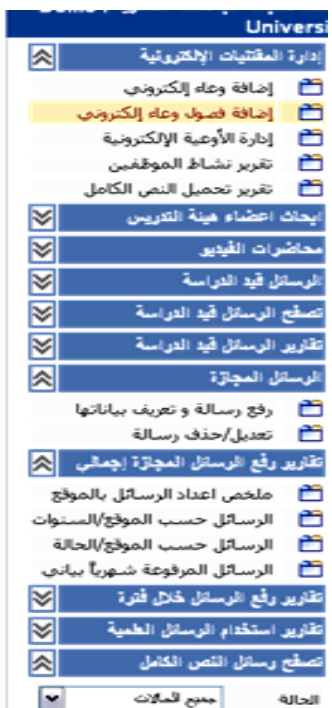

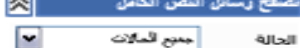

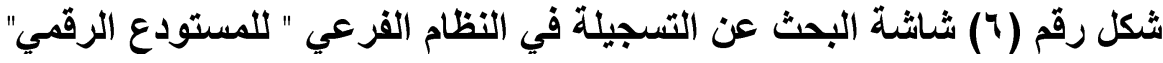

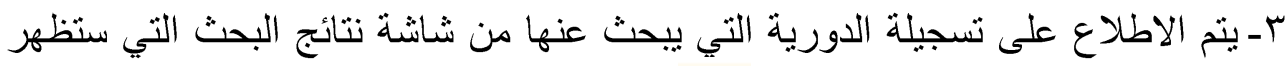

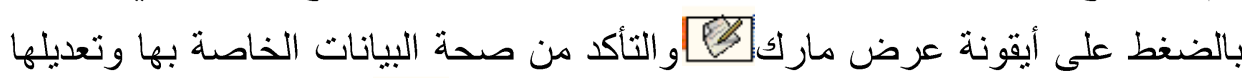

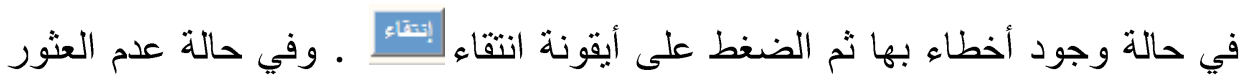
على تسجيلة الدورية المستهدفة تنشأ تسجيلة لها وفقا لمعيار ضبط جودة تسجيلات

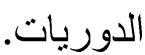




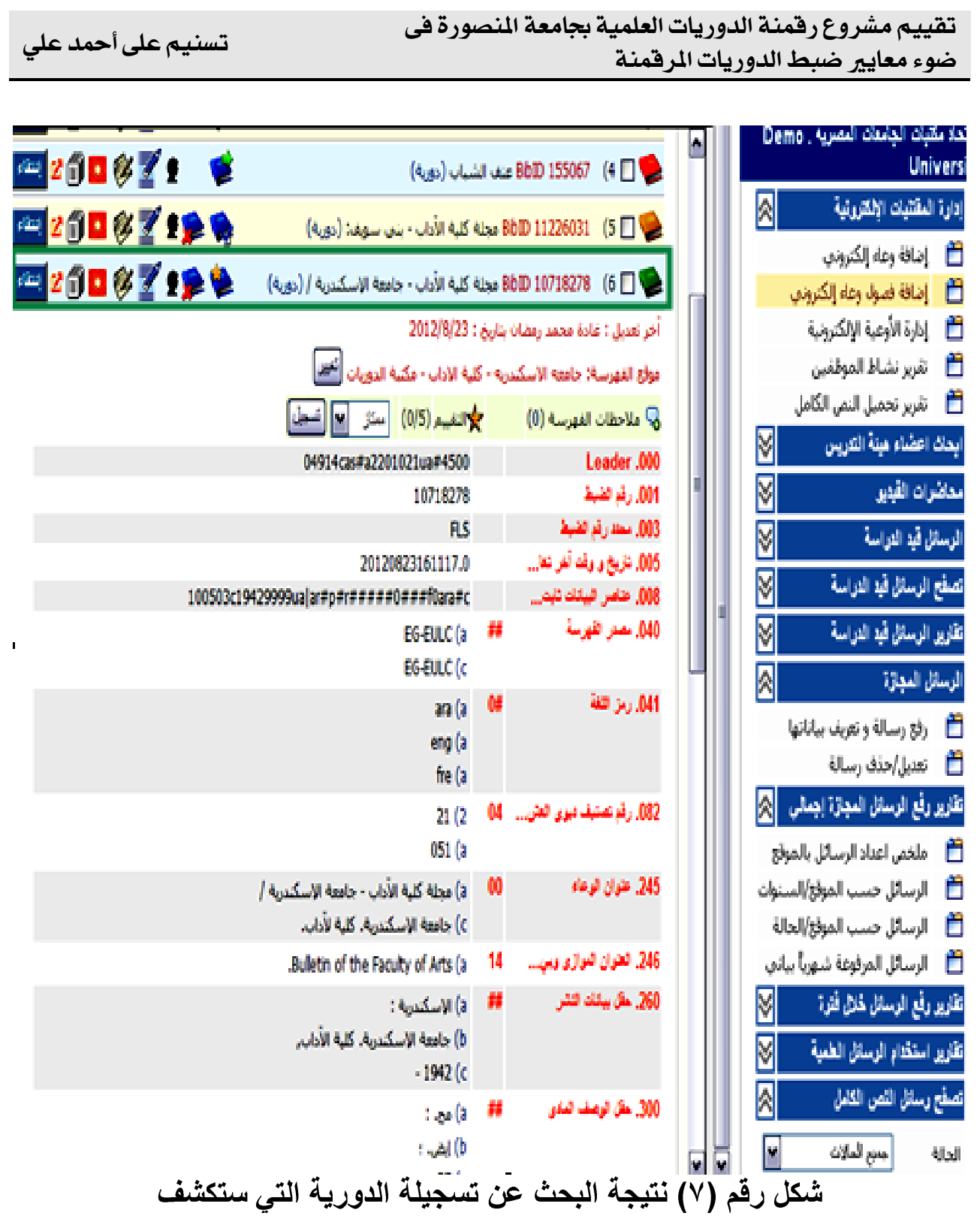

\begin{tabular}{|c|c|c|c|}
\hline$\gamma$ & نعم & البحث و الاسترجاع & عدد البنود \\
\hline$\sqrt{ }$ & & 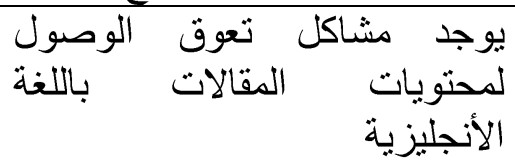 & 1 \\
\hline$\sqrt{ }$ & & لمحتوبات مشاكل ت تعوق المقات باللغة العربية & $r$ \\
\hline$\sqrt{ }$ & & ذات العلاقة بمصية الإحالة للأدوريات البحث & $r$ \\
\hline
\end{tabular}




\begin{tabular}{|c|c|c|c|}
\hline$(Y \cdot) V_{u}$ & & ب عين شمس & حوليات \\
\hline \multirow[t]{2}{*}{$\sqrt{ }$} & & 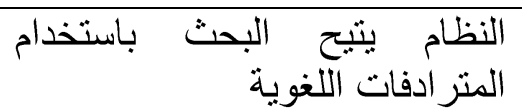 & $\varepsilon$ \\
\hline & $\sqrt{ }$ & للوصول لمحتويات النّورية البحث المتقدم & 0 \\
\hline \multirow[t]{2}{*}{$\sqrt{ }$} & & المرقمن بسمح بالبحث داخل النص & .7 \\
\hline & $\sqrt{ }$ & يتيح النظام البحث بلغات التكثيف & 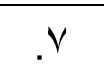 \\
\hline \multirow[t]{9}{*}{$\sqrt{ }$} & & يتيح النظام البحث بالوسائط &.$\wedge$ \\
\hline & $\sqrt{ }$ & بتيح النظام البحثث عن طريق البولينية & 9 \\
\hline & $\sqrt{ }$ & 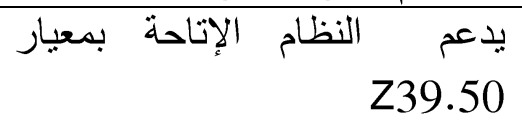 & .1. \\
\hline & $\sqrt{ }$ & 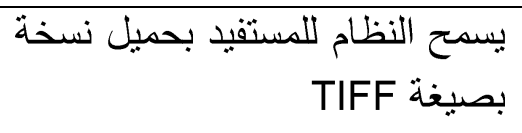 & 11 \\
\hline & $\sqrt{ }$ & 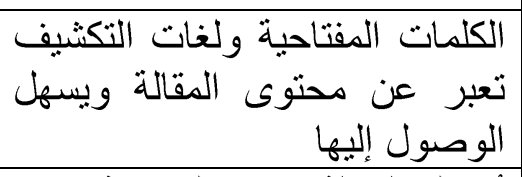 & $.1 Y$ \\
\hline & $\sqrt{ }$ & 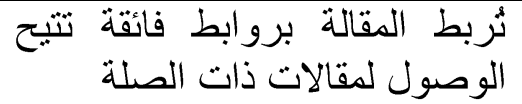 & $.1 \pi$ \\
\hline & $\sqrt{ }$ & عرضيح النظام البحث بـن في من واجهة & $.1 \varepsilon$ \\
\hline & $\sqrt{ }$ & تثم الإتاحة من خلال الخط المباشر & .10 \\
\hline & $\sqrt{ }$ & المباشر بمبنى الإتاحة من خكتلة ب الخط غير & .17 \\
\hline$\sqrt{ }$ & & 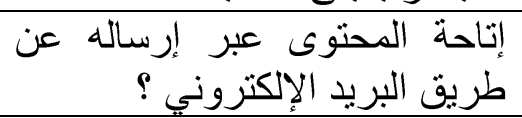 & $.1 \mathrm{~V}$ \\
\hline \multirow[t]{3}{*}{$\sqrt{ }$} & & 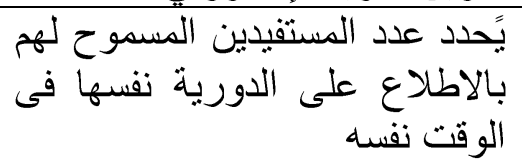 & .11 \\
\hline & $\sqrt{ }$ & ستر للاطلاع وجود على الدوريات مستقبد وكلمة & .19 \\
\hline & $\sqrt{ }$ & $\begin{array}{r}\text { تتم الإتاحة بصيغة الوثيقة المحملة } \\
\text { (Adobe Acrobat) }\end{array}$ &.$r$. \\
\hline$\sqrt{ }$ & & 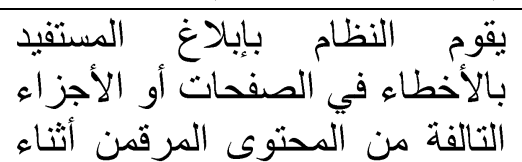 &.$Y^{\prime}$ \\
\hline
\end{tabular}




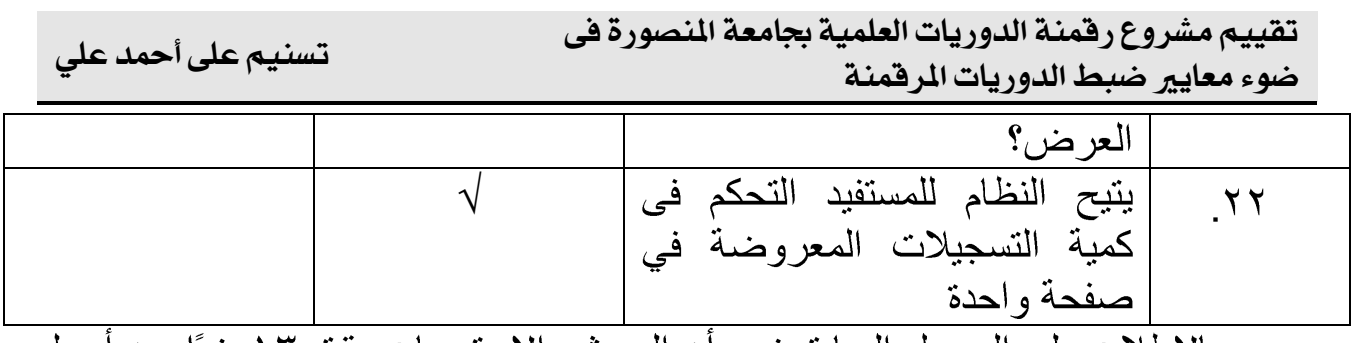

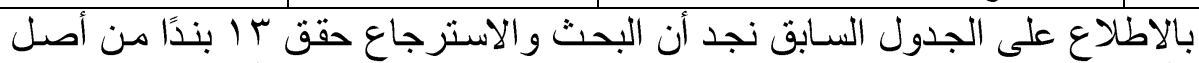

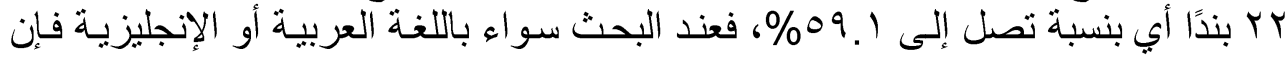

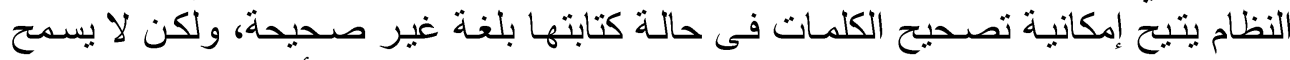

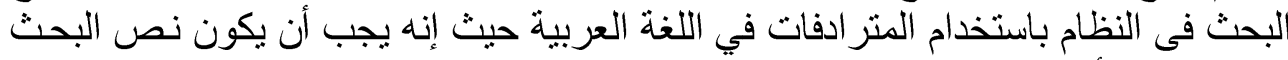

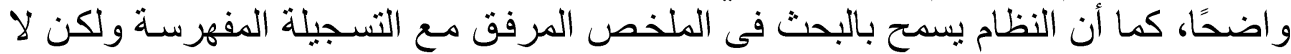

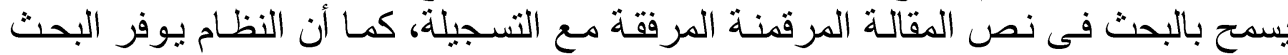

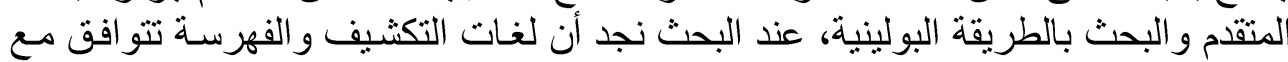

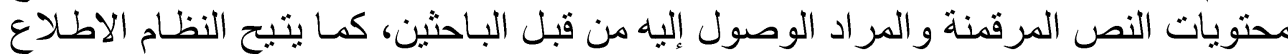

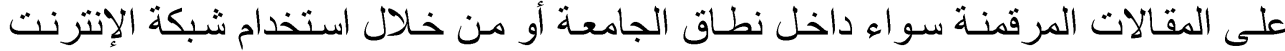

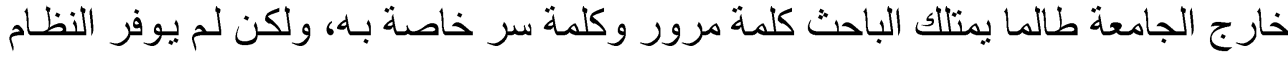

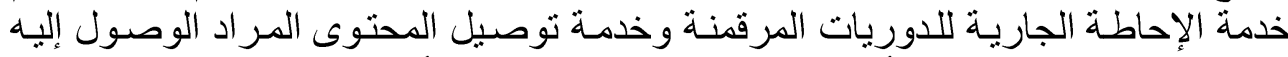

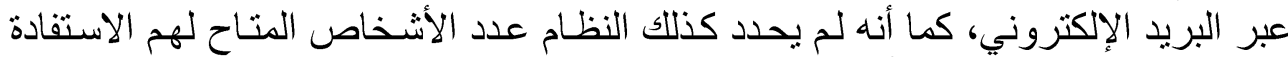

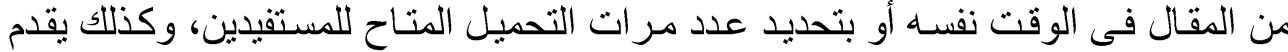

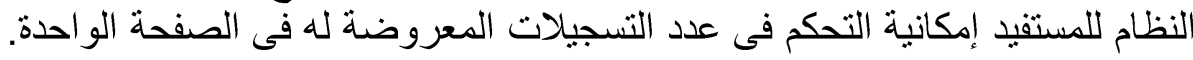

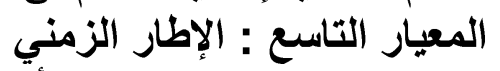

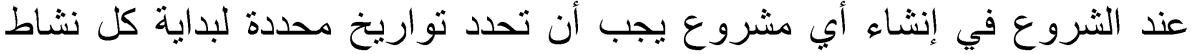

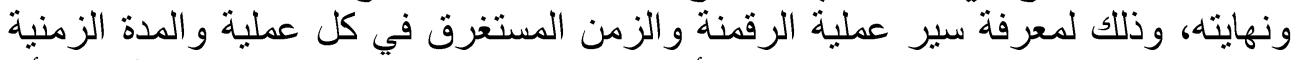

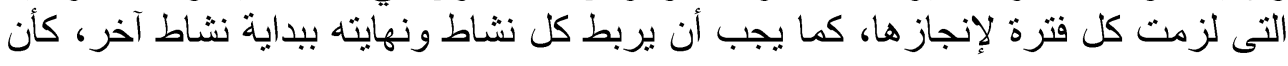

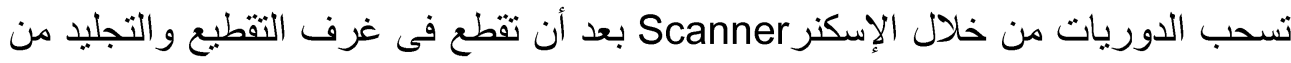

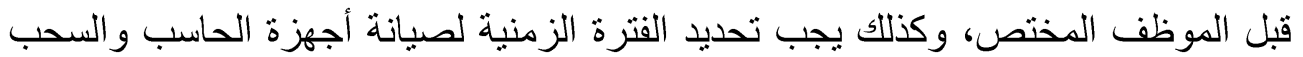
و البرمجيات لضمان جودة عملية الرقمنة.

\begin{tabular}{|c|c|c|c|}
\hline \multicolumn{4}{|c|}{ جدول (0 1) الإطار الزمني } \\
\hline$y$ & نعم & الإطار الزمني & عدد البنود \\
\hline & $\sqrt{ }$ & حددت بداية كل نشاط ونهايته & .1 \\
\hline & $\sqrt{ }$ & لقهر سة دورية حل مسموح استغر اقه & $r$ \\
\hline & $\sqrt{ }$ & 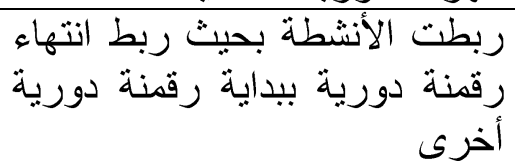 & $r$ \\
\hline & $\sqrt{ }$ & البرمدية عمر الأجهزة والمعدات & . \\
\hline$\sqrt{ }$ & & حدد ميعاد لصيانة الأجهزة & .0 \\
\hline
\end{tabular}

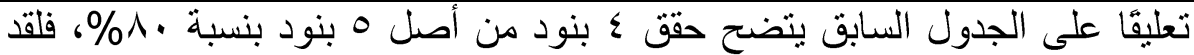

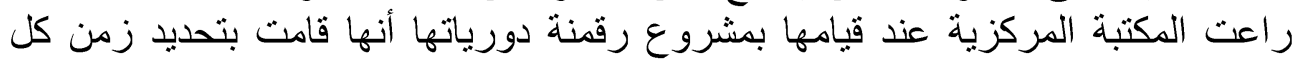




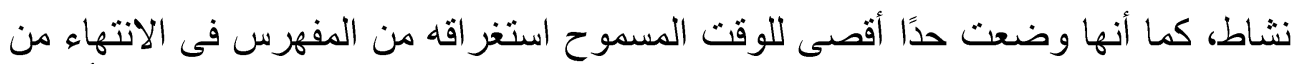

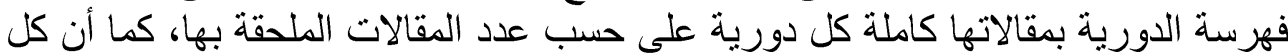

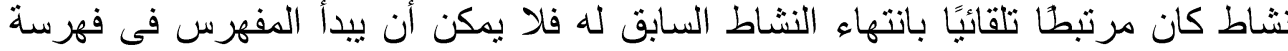

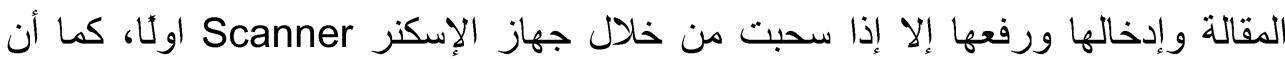

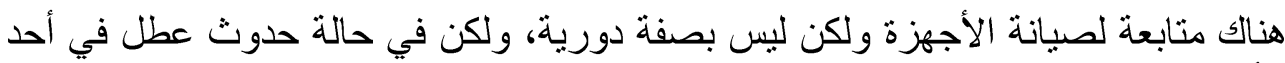

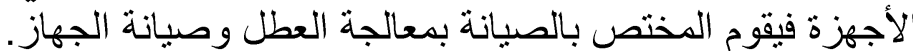

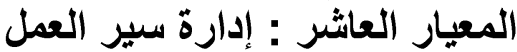

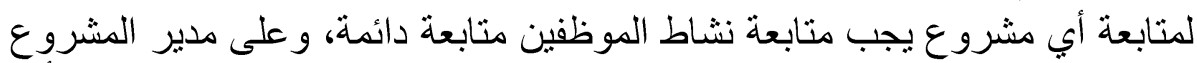

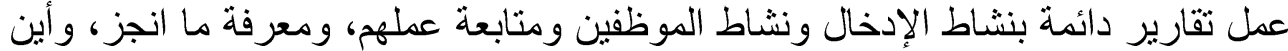

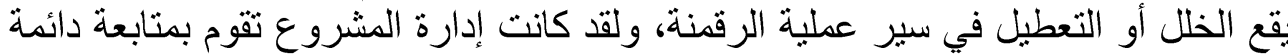

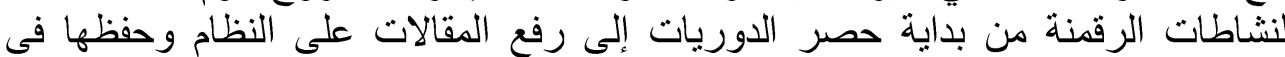

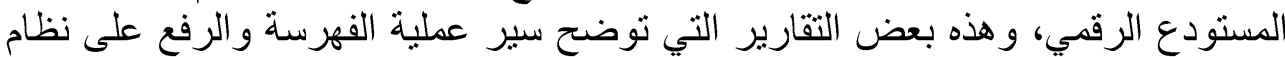

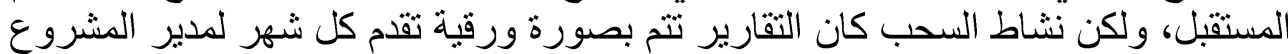

جدول (آ آ) إدارة سير العمل

\begin{tabular}{|c|c|c|c|}
\hline$y$ & نعم & إدارة سير العمل & عدد البنود \\
\hline$\sqrt{ }$ & & والمستح الضوى جودة عملية الرقمنة & 1 \\
\hline & $\sqrt{ }$ & البيليوجر افية على جودة التسجيلات &.$r$ \\
\hline & $\sqrt{ }$ & تقدم تقارير شهرية لمدير المشروع & $r$ \\
\hline & $\sqrt{ }$ & سيرع بالعامليين بالمشروع لمناقشة & $\varepsilon$ \\
\hline & $\sqrt{ }$ & داخل عملية الرقمنة تقارية كل موظف & .0 \\
\hline
\end{tabular}

بالنظر إلى جدول إدارة سبر العمل نجد أنها حققت ؟ بنود من أصل ه ه بند أي بنسبة

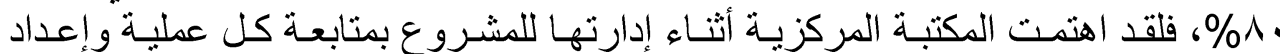

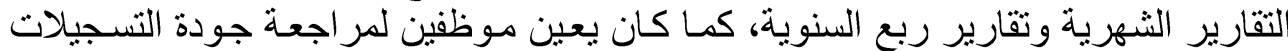

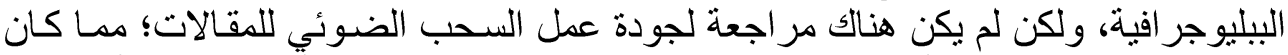

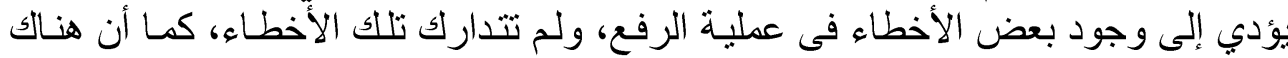

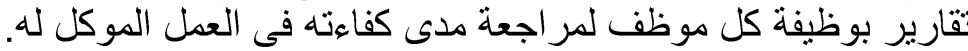
ع/ء نتائج التقييم

حُددت المعايير التي حققها مشروع التحول الرقمي للدوريات في جامعة المنصورة

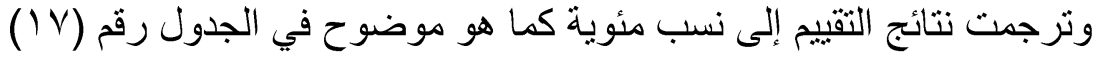

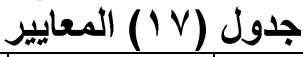

\begin{tabular}{|c|c|c|c|c|}
\hline النسبة المئوية & معدل التحقيق & المعايير & المعيار & r \\
\hline$\% \wedge$ \%.r & 1. & IY & الرؤية و المهمة & 1 \\
\hline$\% \pi r .0$ & 7 & $\Lambda$ & ميز انية المشروع & $r$ \\
\hline
\end{tabular}




\begin{tabular}{|c|c|c|c|c|}
\hline \multicolumn{2}{|c|}{ تسنيم على أحمد علي } & \multicolumn{3}{|c|}{ ضقييم مشروع رقير الدوريات الدوريات العلمية بجامعة المنصورة في } \\
\hline$\%\{1 . V$ & 0 & it & حقوق الملكية الفكرية & $r$ \\
\hline$\% 77 . V$ & $\varepsilon$ & 7 & الموارد البشرية & $\varepsilon$ \\
\hline$\% 77 . V$ & 1. & 10 & العتاد و التجهيز ات & 0 \\
\hline$\% 71 . \vee 0$ & 11 & 17 & تجهيز ات الإعداد و الحفظ & .7 \\
\hline$\% 71 . \vee 0$ & 11 & 17 & الضبط الببليوجر افي &.$V$ \\
\hline$\% 09.1$ & $\pi$ & rr & البحث والاسترجاع &.$\wedge$ \\
\hline$\% \wedge$. & $\varepsilon$ & 0 & الإطار الزمني & .9 \\
\hline$\% \wedge$. & $\varepsilon$ & 0 & إدارة سير العمل & 1. \\
\hline$\% \wedge r .91$ & $\mathrm{Vq}$ & $11 \mathrm{~V}$ & المجموع & \\
\hline
\end{tabular}

بالتعليق على الجدول التالي يتضح أن مشروع التحول الرقمي للاوريات قيم لقياس

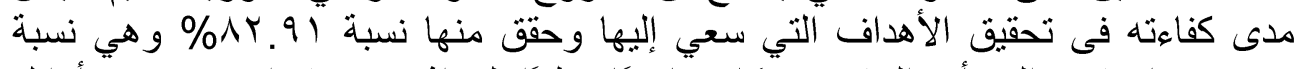

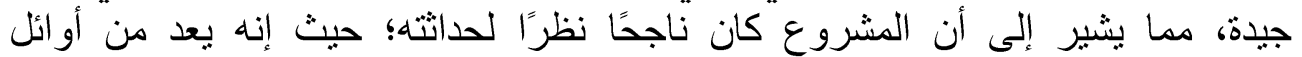

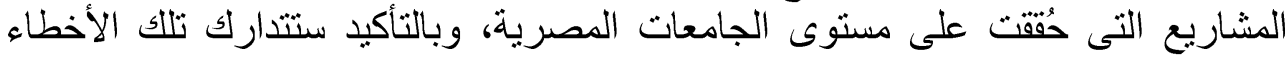
وتعالج ويُعمل على تطوير المشروع. النتائج :

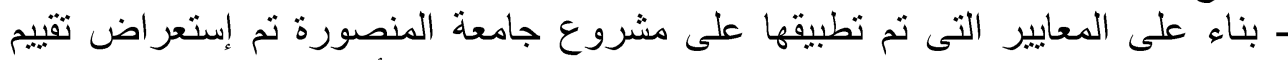

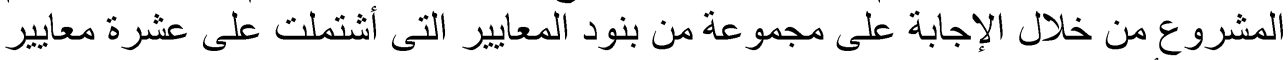

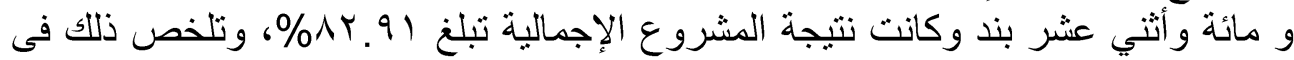
ما يلى : مائل :

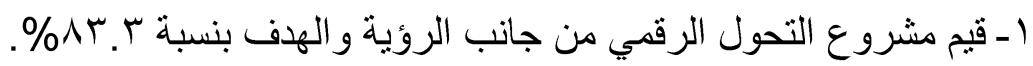

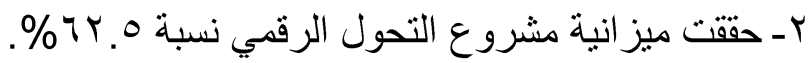

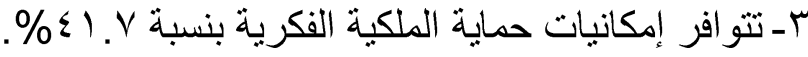

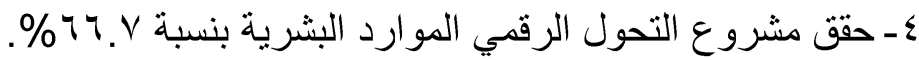

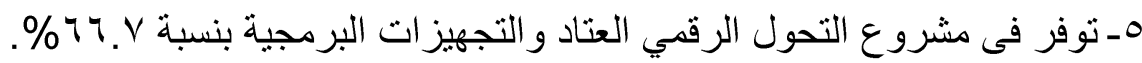

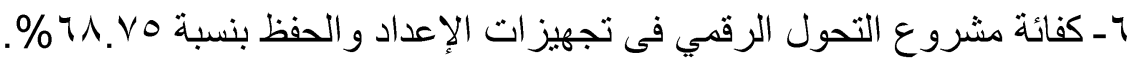

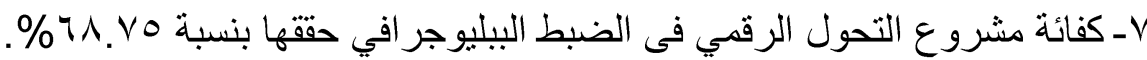

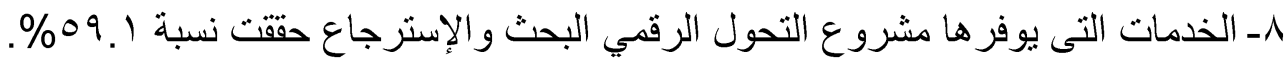

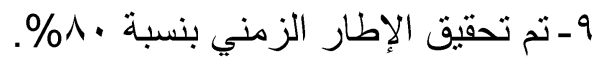

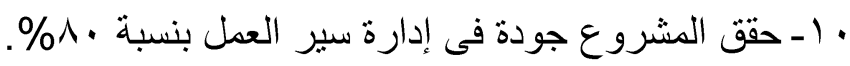

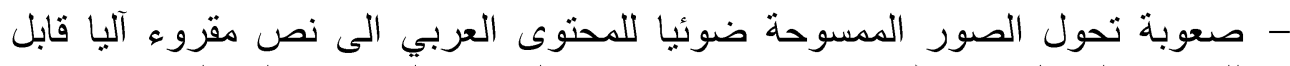

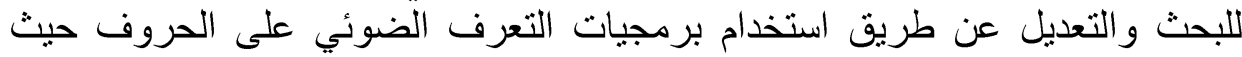

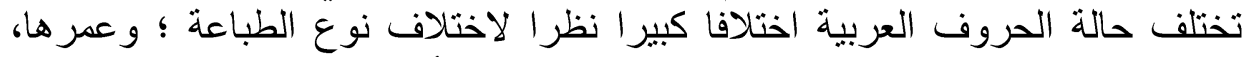

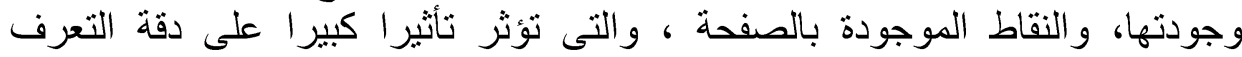


الضوئي الفعلي على الحروف مما يؤدي احيانا الى استحالة عملية التعرف و الاكتفاء

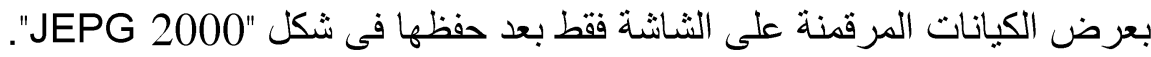

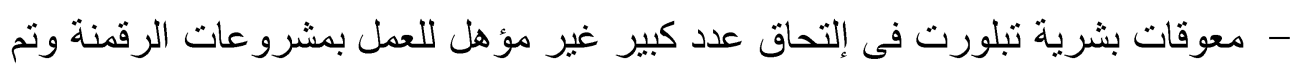

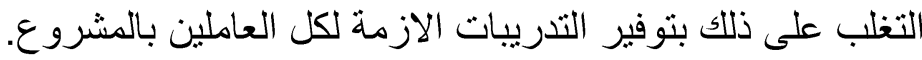
- معوقات مادية تمثلت فى حجم الاستثمار ات المطلوبة لتغطية تكاليف عملية الرقمنة

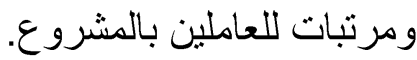

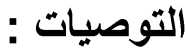

من خلال معايشة الباحثة للمشروع ومراحل تنفيذه والاحاطة التامة بكل اوجها

$$
\text { الايجاب والقصور فية، فمن الممكن الخروج باللتوصيات التالية :- }
$$

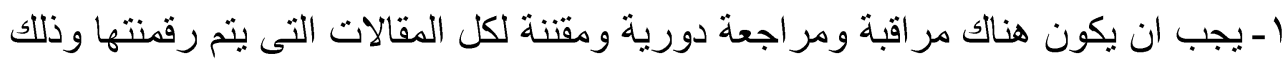

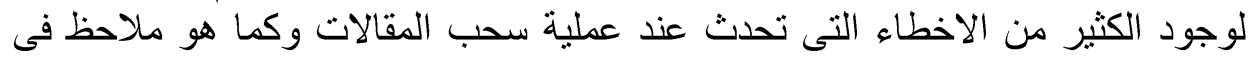
الدر اسة فى التباين الواضح بين عدد المقالات التى تقتيها الجامعة و عدد مقالات المتاحة

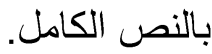

r- ضعف الميز انية أدي الى عدم اهتمام العاملين بجودة الناتج من عملية الرقمنة و التركيز

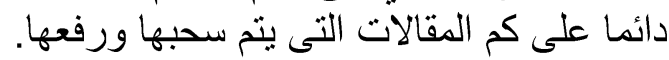

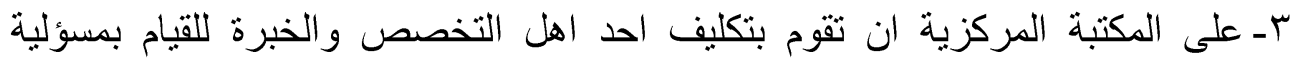

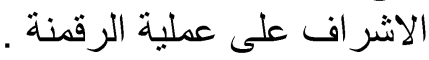

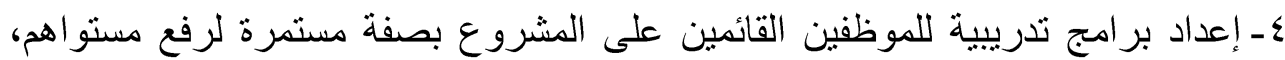

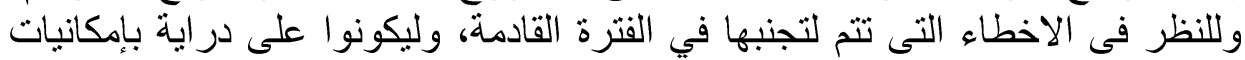
تكنولوجيا المعلومات وتطبيقهاء الاتهات هـ ضرورة توفير مخصصات مالية مستقله ودائمة، الامر الذي يساعد على نجاح المشروع وتحقيق أهدافة. 7 ـ تأمين صبانة البرمجيات و الثبكات و التجهيز ات الإلكترونية وتطوير ها.

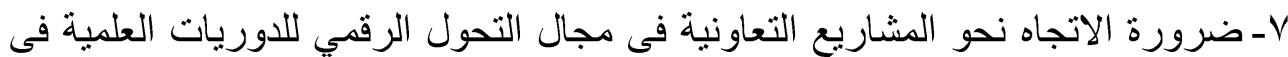

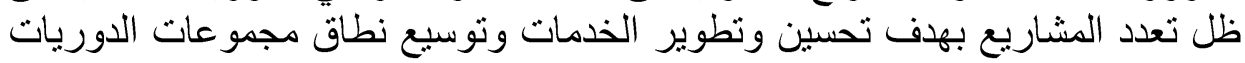
العلمية المتاحة للمستقيدين. ᄉـ العمل على ربط مخرجات المكتبة المركزية من مقالات الدوريات بقواعد العد البيانات العالمية وذلك للعمل على رفع تقييم جامعة المنصورة المنية عالميا. 


\section{Abstract \\ Evaluation of the digitization project of scientific journals at Mansoura University in light of the standards \\ By Tasneem Ali Ahmed Ali}

The study aims to assess the project to digitize scientific journals in Mansoura University in the light of the criteria, and formed the criteria of 10 key criteria, covering 104 indicator, and extracted with these standards Icon sincerity acceptable and consistency for the purposes of this study, followed by the application of the standards on the digitization project at Mansoura University and then conducted a statistical analysis of the results, the study results suggest: the achievement of the central criteria library increased by $68.75 \%$ in aggregate, the values of the project digital transformation of the vision and the goal of $90 \%$, while the achieved project digital transformation budget achieved a rate of $62.5 \%$, and available possibilities of intellectual property protection by $41.7 \%$, achieved the transformation project Digital human resources by $66.7 \%$, the availability in the project of digital switching gear and supplies software by $66.7 \%$, the efficiency of the project digital transformation in the preparation and conservation equipment increased by $68.75 \%$, the efficiency of the project digital transformation in the disciple bibliographic achieved by $68.75 \%$, the services provided by the project digital transformation Search Returns and achieved a rate of 59.1\%, was achieved both the timeframe and quality in workflow management by $80 \%$.

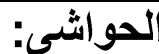

1John McIlwaine, Guidelines for Digitization Projects for collections and holdings in the public domain, particularly those held by libraries and archives (draft) : John McIlwaine, Jean-Marc Comment, Clemens de Wolf .. ect . IFLA, 2002

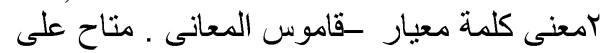

http://www.almaany.com/home.php?language=arabic\&lang_name=\%D8\%B9\%D8\%B1 في 10/4/2014

$$
\begin{aligned}
& \text { كحمد الريج. مدخل المعايير في التعليم: من مستجدات تطوير المناهج وتجويد المدرسه .منتديات بوابة }
\end{aligned}
$$

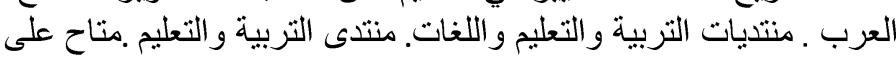

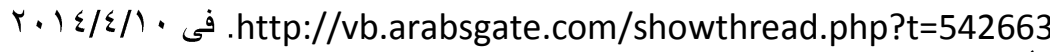

$$
\begin{aligned}
& \text { ع أسامة محمود فؤاد ـ تعريف المعاييز والمؤشرات . متاح على . مائى }
\end{aligned}
$$

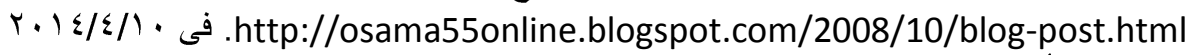

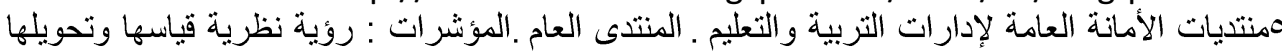

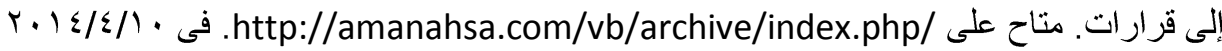

$$
\begin{aligned}
& \text { اجبريل بن حسن العريش، وفاتن بنت سعيد بامفلح."نحو إنشاء مكتبة رقمية للاوريات العلمية العربية }
\end{aligned}
$$

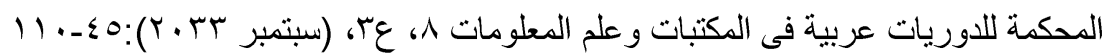

$$
\begin{aligned}
& \text { Vاطف السيد قاسم. حفظ وصيـانة المعلومات الالكترونية فى المكتبات المصرية : دراسة تحليلية للمفاهيم }
\end{aligned}
$$

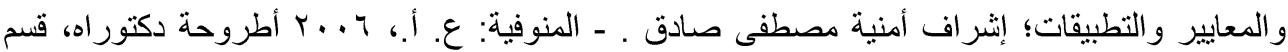

$$
\begin{aligned}
& \text { المكتبات و المعلومات، جامعة المنوفية. }
\end{aligned}
$$




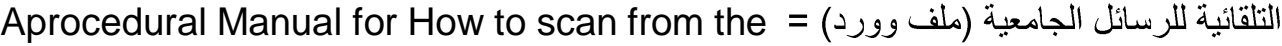
.automatic feeder (ADF) for Academic Theses

IrShireman, scanning your stuff , 12 rا اكلية الزراعة ـ مجلة العلوم الزراعية ـ متاح في:

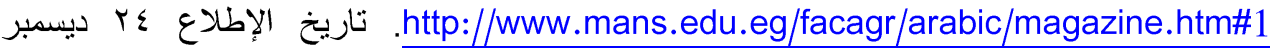
$r+11$

ع أكلية التجارة ـ المجلة المصرية للار اسات التجارية ـ متاح في:

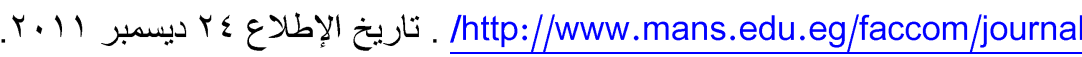

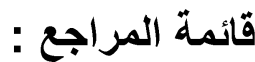

l. أبوالخير، تامر محمد ـ الجودة الثاملة وتقييم الأداء في المكتبات الأكاديمية :تجربة كلية الأمير سلطان

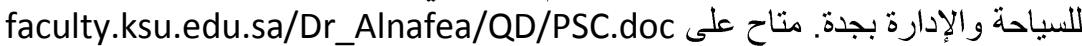

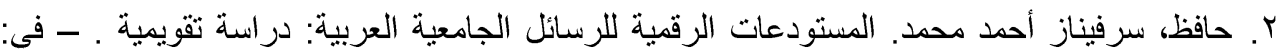

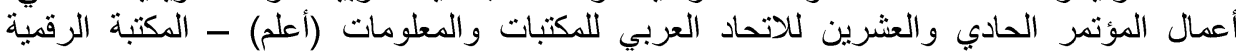

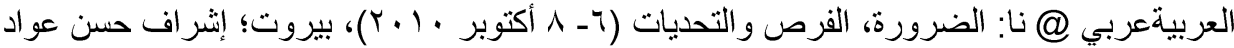

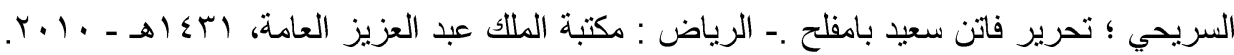
OrV - 291 ص

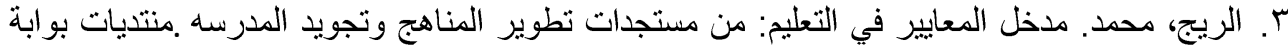

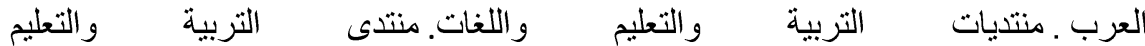
متاحعلى

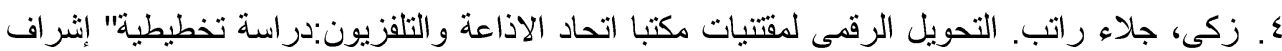

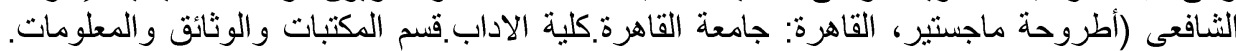

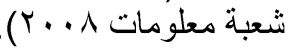
ه. العريش، جبريل بن حسن، وفاتن بنت سعبد بامفلح."نحو إنثاء مكتبة رقمية للاوريات العلمية العربية

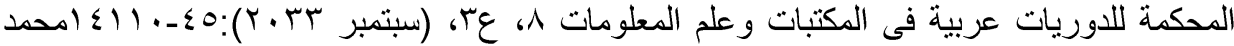

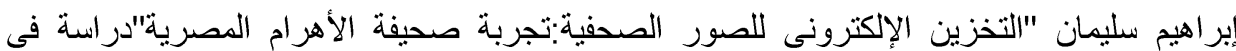

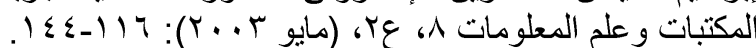

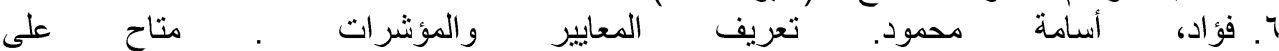
r. أ. http://osama55online.blogspot.com/2008/10/blog-post.html

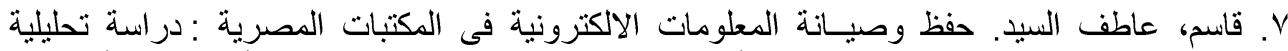

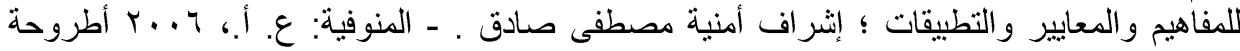

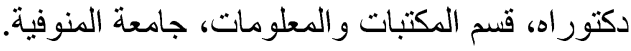
ي ـ. كلية الزراعة ـ مجلة العلوم الزراعية ـ متاح في: http://www.mans.edu.eg/facagr/arabic/magazine.htm\#1 $r+11$ 9. كلية التجارة ـ الدجلة الدصرية للار اسات التجارية ـ متاح في:

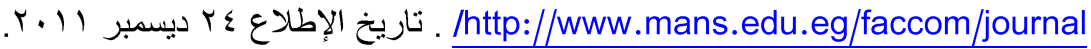




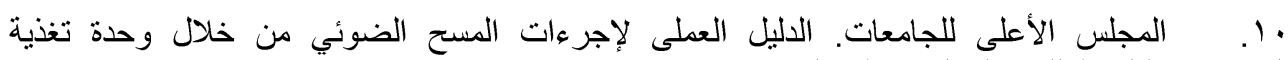

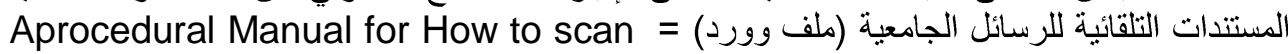
.from the automatic feeder (ADF) for Academic Theses

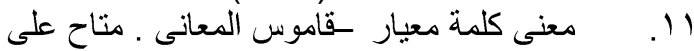

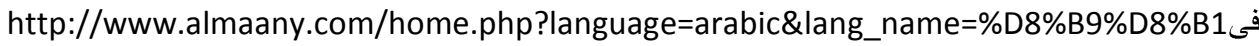
10/4/2014

rا. منتديات الأمانة العامة لإدارات التربية والتعليم ـالمنتدى العام .المؤشرات : رؤية نظرية قياسها

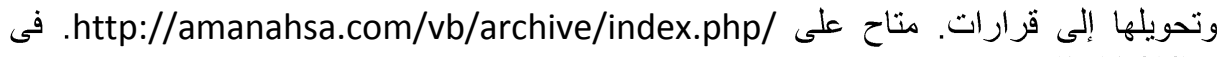
$r \cdot \mid \tau / \varepsilon / 1$.

13. John McIlwaine, Guidelines for Digitization Projects for collections and holdings in the public domain, particularly those held by libraries and archives (draft) : John McIlwaine, Jean-Marc Comment, Clemens de Wolf .. ect . IFLA , 2002 